MLM-MU-89-65-0012

\title{
An Investigation of Bridge Width Measurement and Processing Capabilities (1985)
}

Compiled by Kenneth P. Armstrong

May 15, 1989

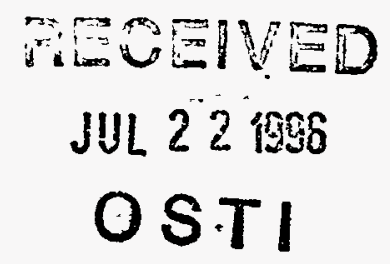

\section{MOUND}

\section{operated by}

EGRE MOUND APPLIED TECHNOLOGIES

P.O. Box 3000, Miamisburg, Ohio 45343-0987

for the

U. S. DEPARTMENT OF ENERGY

Contract No. DE-AC04-88DP43495 


\section{DISCLAIMER}

This report was prepared as an account of work sponsored by an agency of the United States Government. Neither the Uniteid States Government nor any agency thereof. nor any of their employees. makes any warranty. express or implied. or assumes any legal liablity of responsiblity for the accuracy. completeness. or usefulness of any information. apparatus. product. or process disclosed. or represents that its use would not infringe privately owned rights. Reference hereln to any speclfic commerclal product. process. or service by trade name. trademark. manufacturer. or otherwise. does not necessarily constitute or imply its endorsement. recommendation. or favoring by the United States Government or any agency thereof. The views and opinlons of authors expressed herein do not necessarily state or reflect those of the United States Government or any agency thereof. 
MLM-MU-89-65-0012

\section{An Investigation of Bridge Width Measurement and Processing Capabilities (1985)}

Compiled by Kenneth P. Armstrong

Issued: May 15, 1989

\section{MOUND}

operated by EE\&G MOUND APPLIED TECHNOLOGIES

P.O. Box 3000, Miamisburg, Ohio 45343-3000

for the

U. S. DEPARTMENT OF ENERGY

Contract No. DE-AC04-88DP43495 


\section{Contents}

\section{Page}

Abstract

3

Introduction $\ldots \ldots \ldots \ldots \ldots \ldots \ldots \ldots \ldots \ldots \ldots \ldots, 3$

Content $\ldots \ldots \ldots \ldots \ldots \ldots \ldots \ldots \ldots \ldots \ldots \ldots \ldots \ldots \ldots \ldots \ldots$

Tape Bridge Data Analysis Memo ................. 4

Tape Bridge Measurement Capabilities Memo ............ 34

Acknowledgments $\ldots \ldots \ldots \ldots \ldots \ldots \ldots \ldots \ldots \ldots \ldots \ldots, 40$

Glossary $\ldots \ldots \ldots \ldots \ldots \ldots \ldots \ldots \ldots \ldots \ldots \ldots \ldots \ldots \ldots \ldots \ldots \ldots$

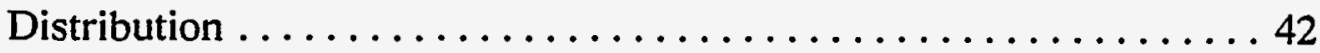




\section{DISCLAIMER}

Portions of this document may be illegible in electronic image products. Images are produced from the best available original document. 


\section{.}




\section{Abstract}

An investigation of Mound's ability to measure and process bridges was conducted in 1985 . Prior to improvements in the measuring system and technique, bridge width was found to have a sigma of 0.00019 in. After improvements were made, a sigma of 0.000047 was realized. Bridge length was found to be more erratic than width, although most of the inaccuracy was caused by measurement uncertainty. Length and width were found to have little or no correlation.

\section{Introduction}

The MC3926 and 1E-38 detonators were developed based on studies conducted by Quality, Production, and Development personnel. In the early stages of the programs, the tape process studies were documented in memos. To formally record these studies and make them easily available to interested persons, these memos are being compiled as Mound technical reports. This report documents research performed by F. H. Scott in 1985.

Scott conducted the studies to investigate Mound's ability to measure bridge width and to determine processing capabilities. The measuring capabilities were discovered using a Vidicom system. A bridge width sigma of 0.00019 in. was found prior to improvements in the measuring system and technique. After the improvements were made, a sigma of 0.000047 in. was realized. The bridge processing capabilities were determined by measuring 23 bridge populations from 12 reels of tape using 2 different phototools.

Several conclusions were drawn from the study. Shifts in the data indicated deliberate adjustments in the process, but no records of these were present. Bridge length was more erratic than width. However, most of the length inaccuracy was a result of measurement uncertainty. Bridge length and width were found to have little or no correlation.

\section{Content}

This report comprises two memos written by F. H. Scott summarizing work performed in the tape process area. These memos are reproduced unedited. This work was performed in 1984-85. Processing and measuring equipment have changed since the data were gathered; therefore, the results may not be valid for current systems. However, to preclude repetition of the research, the results are reported here. 


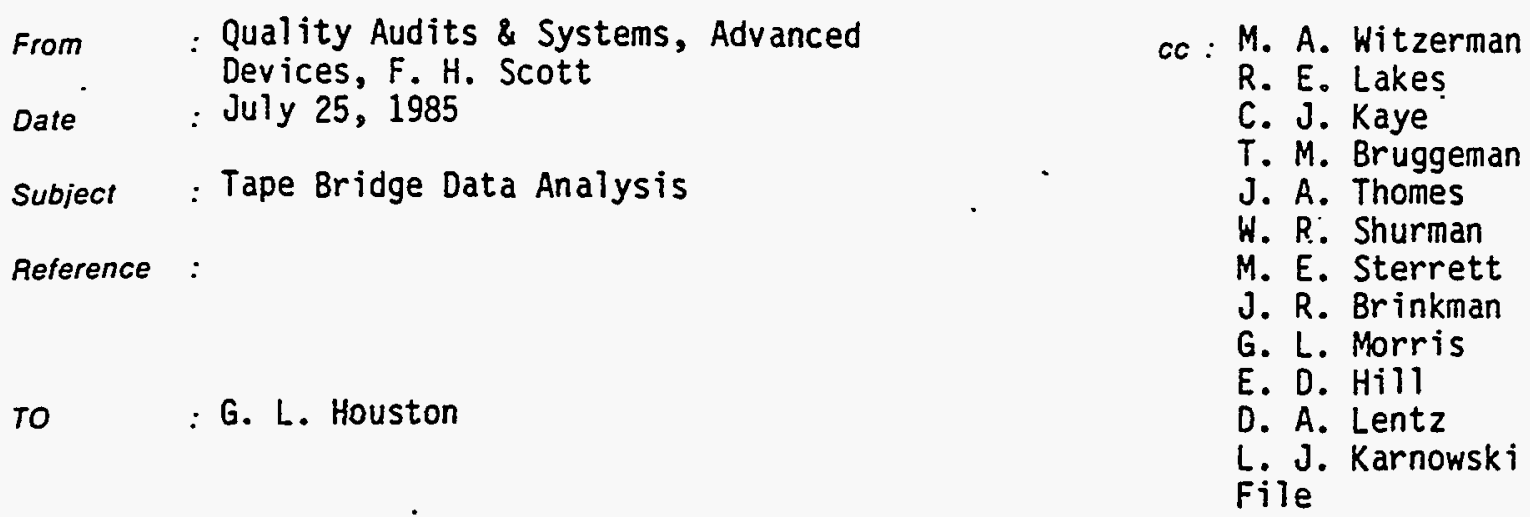

Attached are copies of the graphs I used in our meeting Tuesday, July 23 rd. Following is a summary of the presentation to help assure a common understanding and also to provide a written record for possible future reference.

To assess the capability of the tape bridge process, the dimensional inspection data of 13 receiving inspection reports, representing 23 bridge populations from 12 reels of tape, was analyzed. (All of the reels were square bridges except for receiving report 28 , which was LANL radius bridges.) These reports appear to be all of the data currently available for the November 1984 to June 1985 time period. Extensive efforts were made to trace the data to the correct reel and art work but lack of process area records precluded tracing the identity of the data on three inspection reports. In lieu of process records, it was assumed that the reels were sent to Receiving Inspection in chronological order so the data was ordered by the receiving inspection numbering sequence. This sequence appears to correlate with reel number sequence where the reel numbers could be established.

After ordering the data by receiving inspection sequence the data was subgrouped by photo tool for graphing. Thus, each graph displays the inspection data from a given photo tool across time. (The art work--photo tool--listed for each population is based on the bridge size as determined from the data since no processing records exist listing the photo tool used for each reel. It was subsequently learned that several copies of some tools exist, so the listed tool on the graphs is of doubtful correctness.)

Each graph contains data from only one (?) photo tool except for the graphs of the most recent reels (reels 11, 14, 15, and 16). After the data were graphed it was confirmed that two photo tools had been used in producing these reels. Each graph is annotated with the identification information that could be establi ished.

Except for the three most recent reels $(14,15$, and 16) the complete reel was sent to Receiving Inspection. On the last three reels individual bridges were sent with the sample being selected in the processing area. These samples were fairly limited (especially reels 14 and 15 which were 1.2 and 8 samples respectfully) and were selected in a representative manner rather than a statistically random manner. When the entire reel was sent every 20 th bridge was measured except for report 28 (LANL bridges) where every 10th part was inspected, and report 36 (reel 11) where the interval between inspected bridges varied from 11 to 14. 
The individual readings are plotted on the graphs in sequential order along with. the average $(X-b a r)$ for each population and its three sigma limits. The width and length of individual bridges are of course plotted on separate charts. In addition to the individual plot graphs, regression charts were plotted on six populations to assess the correlation between bridge length and width.

Enclosed along with the individual plots and regression graphs, are a tabulation of data and two summary graphs. The summary graphs (one for length and one for width) provide a comparison of all of the populations across time to indicate progress (or lack there of) in achieving a more uniform and accurate product. To put the data on a single chart it was coded by subtracting from each population's $x$-bar the nominal size of the photo tool. The difference between actual and desired was then plotted along with the three sigma limits for that population; thus, these graphs show lot by lot how close the actual average size came to the desired size, and the data spread around the displacement from desired size.

Some of the more important conclusions drawn from the graphs are:

1. Many of the populations exhibit trends up or down as well as sudden shifts or breaks in the data. Even the most recent reels (which presumably represent the current and best state of the process) show strong up and down trends within the runs, as well as sharp differences between $X$-bars of the different populations. One would like to assume that sharp breaks with in a population (like that of the width data from reel Ea on the photo tool $20 \mathrm{graph}$ ) are due to deliberate adjustments in the process. However, no records exist to establish the cause of the shift so that assumption should not be made.

2. Bridge length is usually more erratic and of less accuracy than is width.

3. Adherence to desired size significantly improved after the first six populations (reel number unknown), however, the variability within each population did not show a similar degree of improvement.

4. The length data on the single reel of radius bridges is very erratic (6 sigma range exceeds .008"). Most of this variability is due to measurement error induced by the difficulty of establshing the true radius blend points. The problem has been called to the attention of Receiving Inspection, but because of the inherent errors in measuring such a short arc it is doubtful that sufficiently accurate radius measurements can ever be made.

5. Bridge length and width have poor or no correlation. Consequently, both attributes will have to be monitored to determine needed process adjustments.

Two recommendations were drawn from the study:

1. Process repeatability and accuracy need to be improved (if the product tolerance remains at the currently specified plus or minus $.0002^{\prime \prime}$ ) if a reasonable yield is to be obtained. 
2. Process records need to be set up to allow correlation of process results with the causative factors.

At the meeting it was suggested that the material thickness (which differed from reel to reel) might correlate with some of the changes in variability found between populations. Subsequent to the meeting a list of thicknesses by reel was obtained. The thickness data was plotted against the sigmas of the populations made from that material to evaluate correlition. As you can see on the enclosed hand plot, no correlation exists between product variability and material thickness. (At least for these material thicknesses.)

If you have any questions or if I can provide any additional information please contact me.

FHS/gC

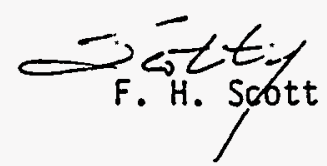




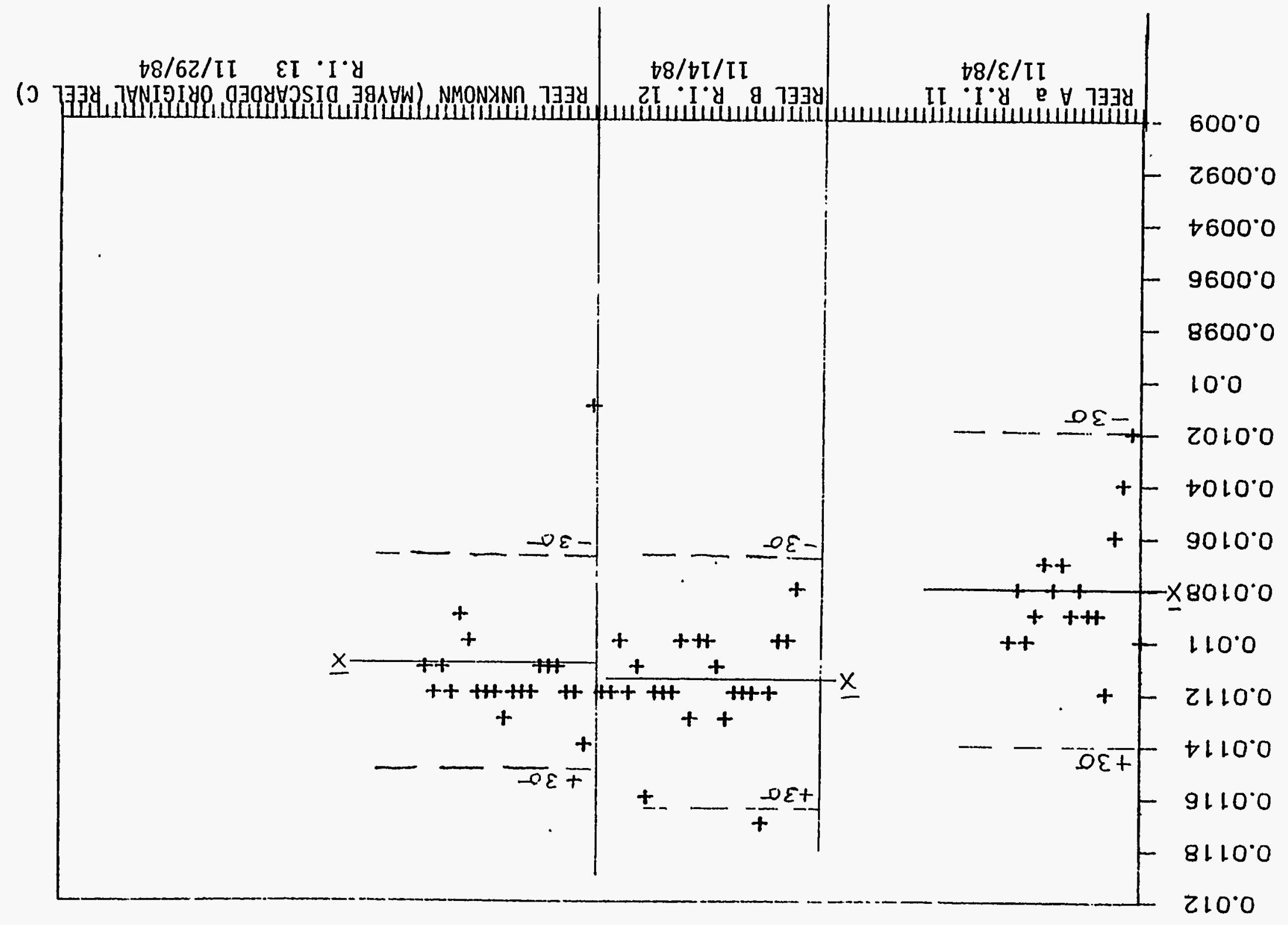


PHOTO TOOL $19(.010 \times .010 ")$

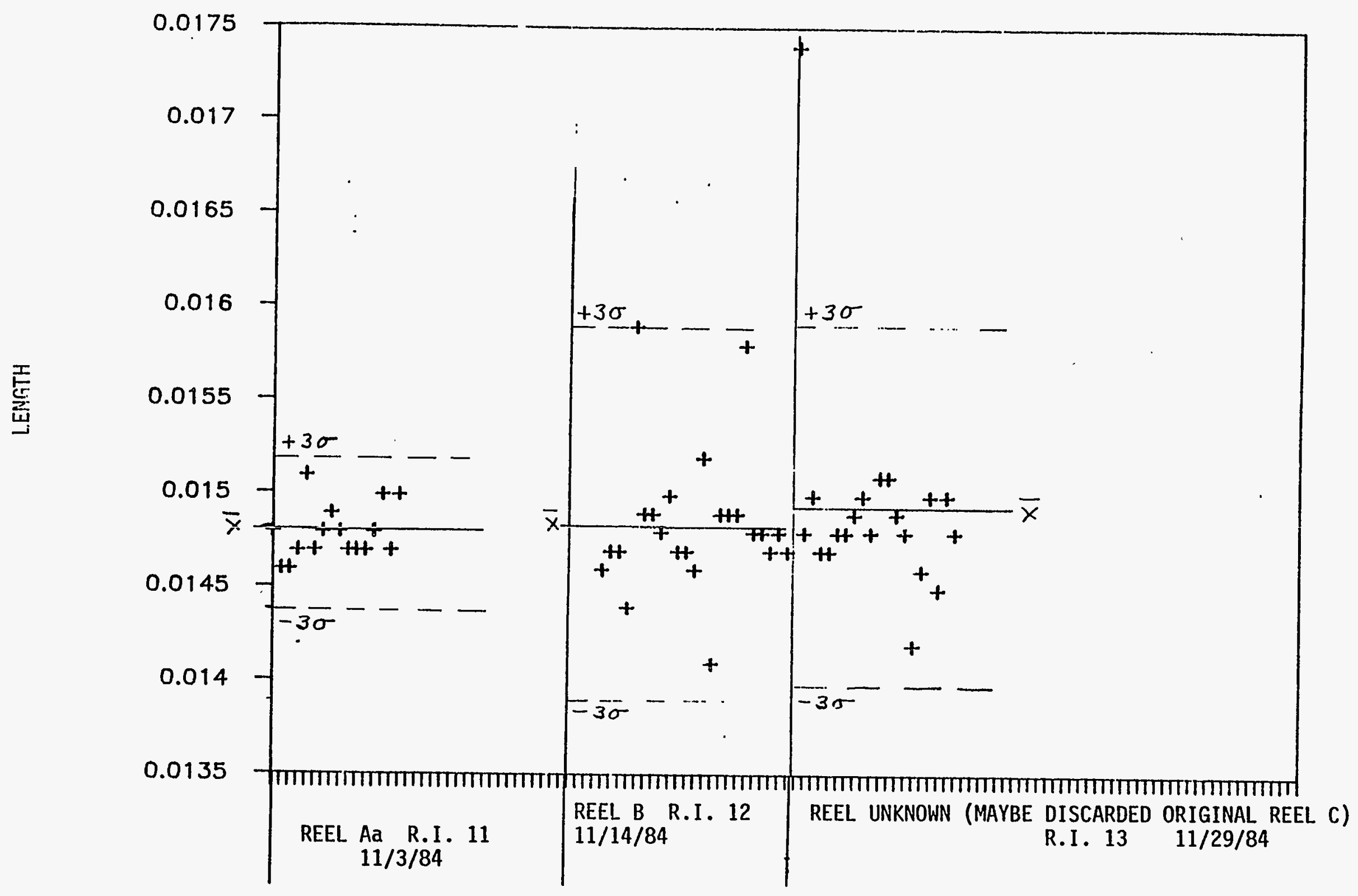




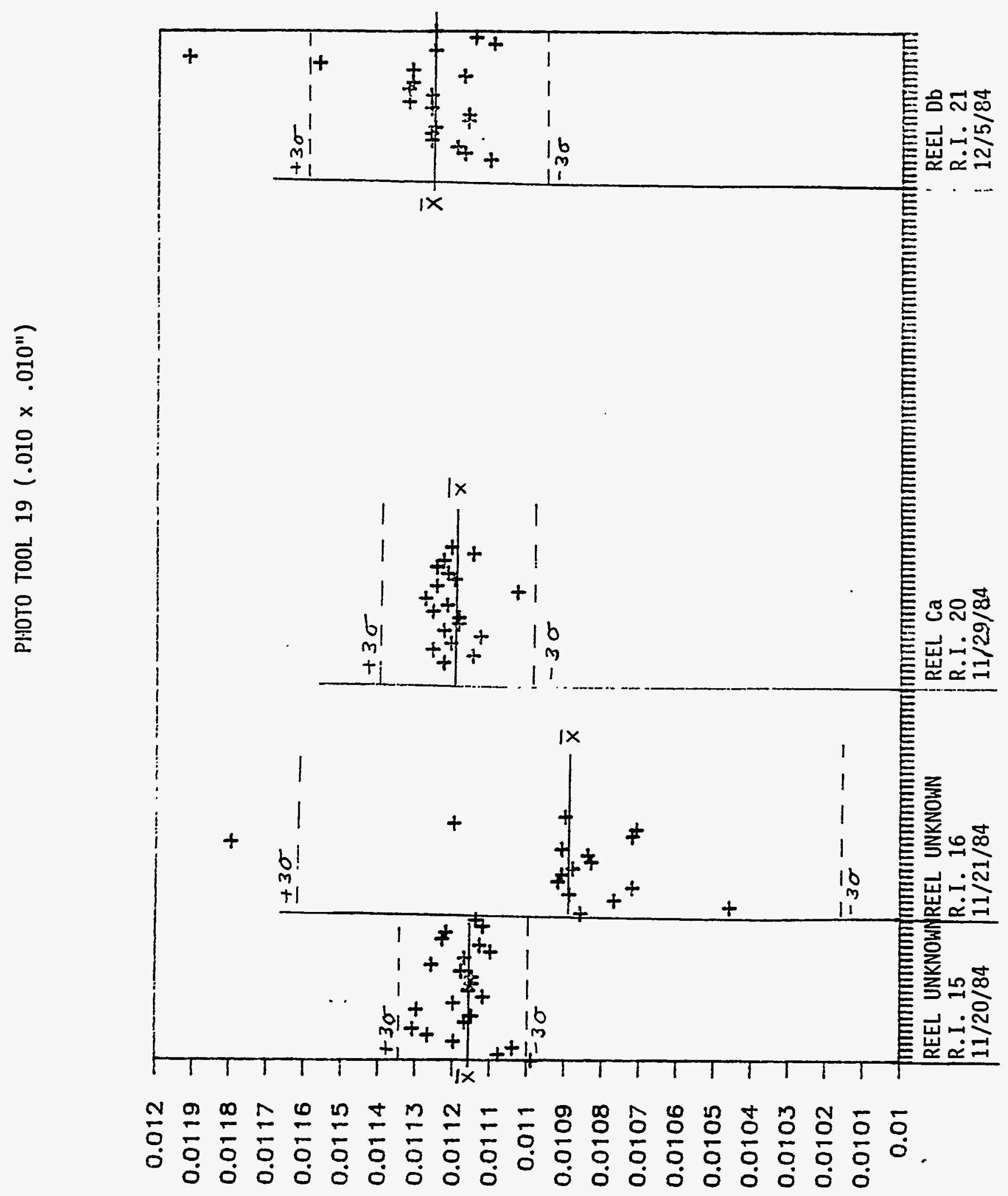


PHOTO TOUL $19\left(.010 \times .010^{\prime \prime}\right)$

$\overrightarrow{0}$

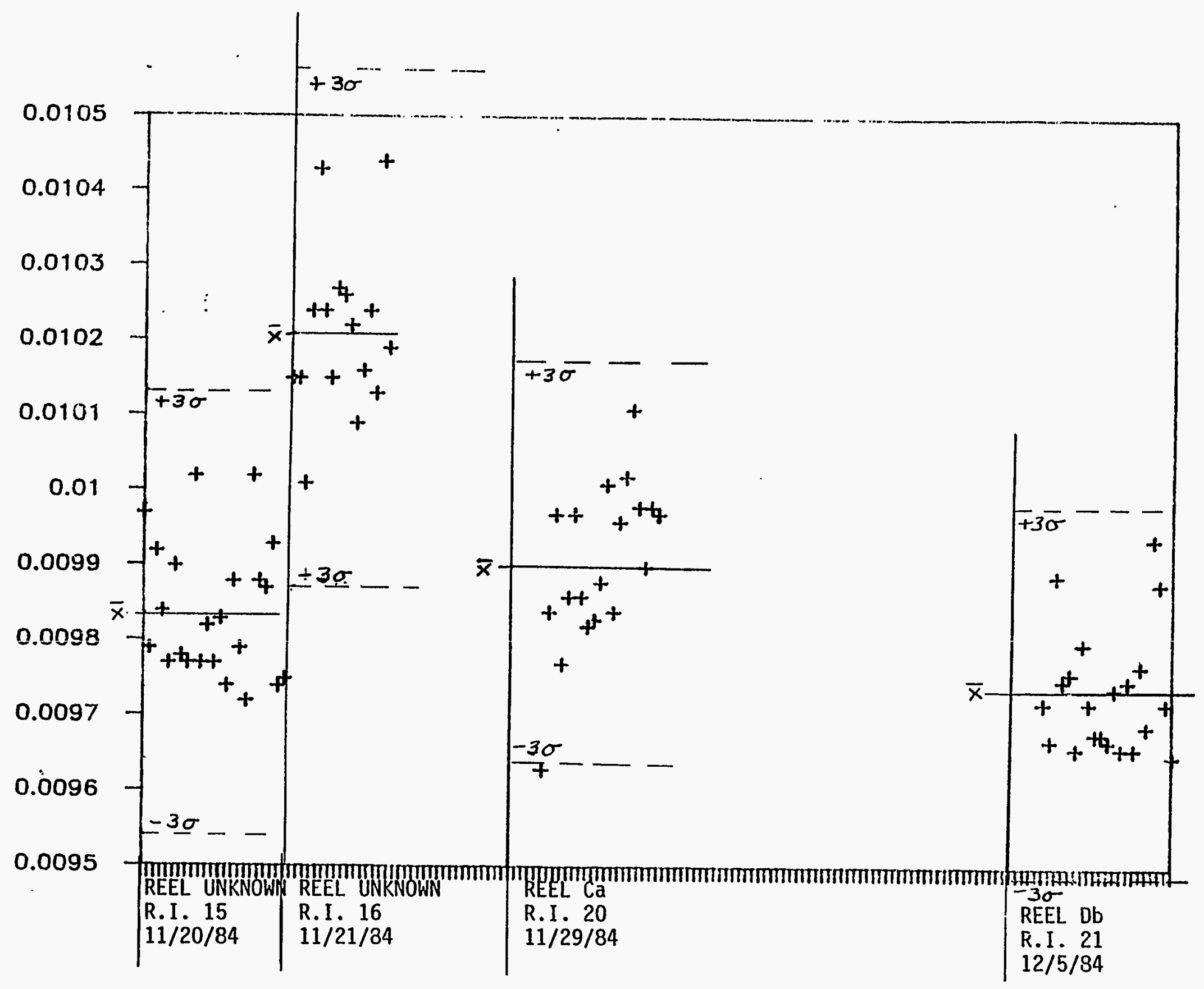


PHOTO TOOL $20\left(.015 \times .015^{\prime \prime}\right)$

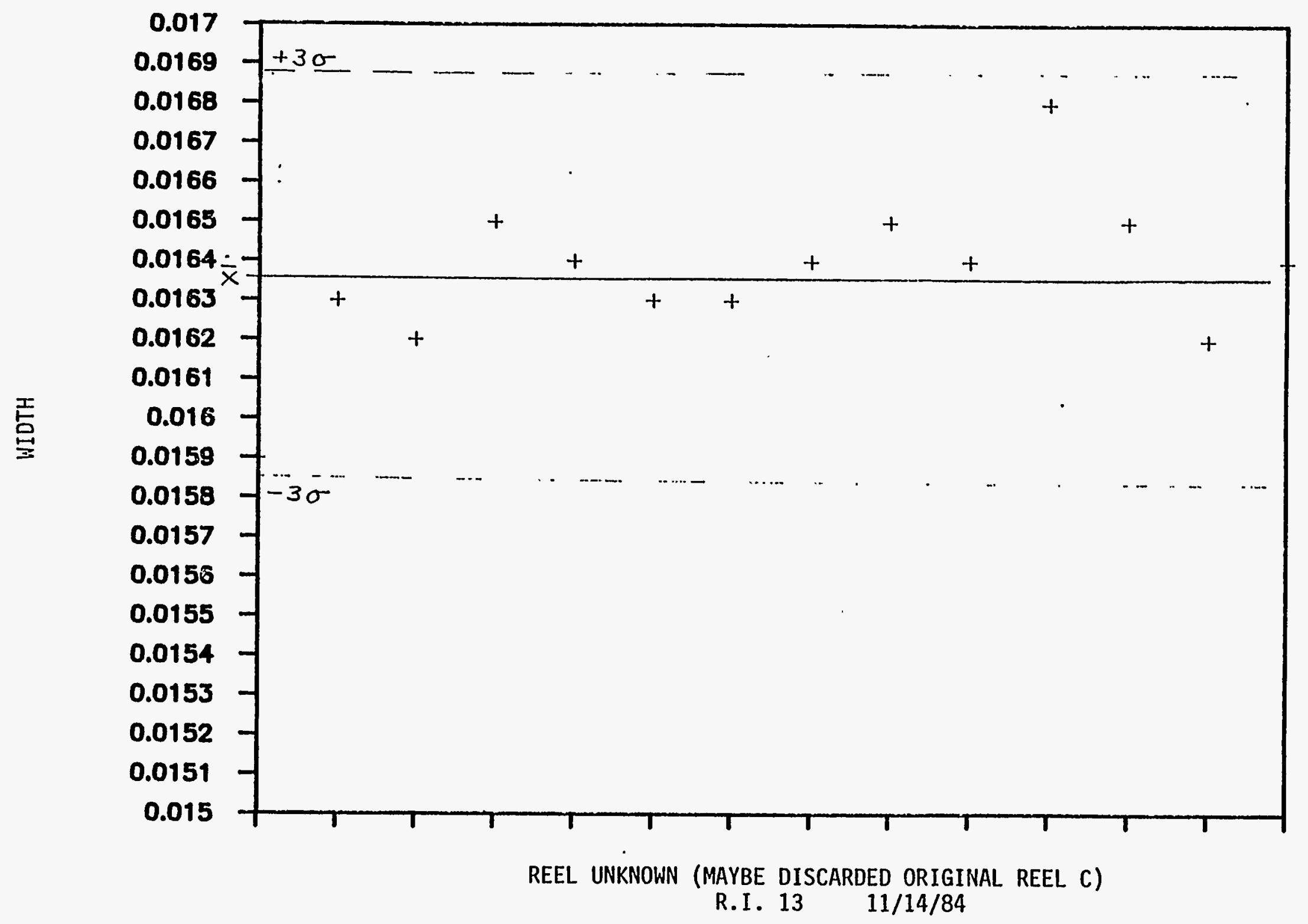




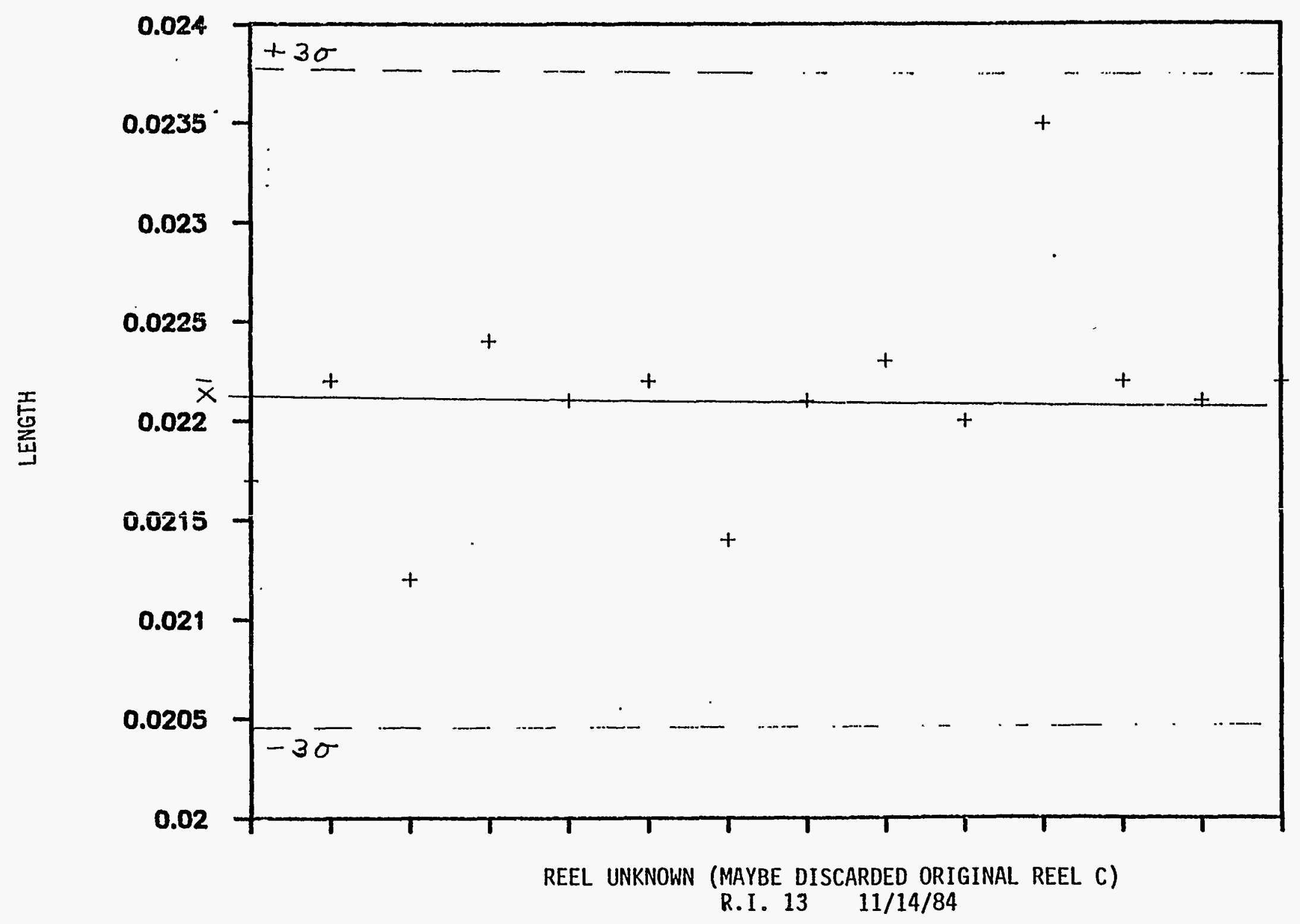


PHOTO TOOL $20\left(.015 \times .015^{\prime \prime}\right)$

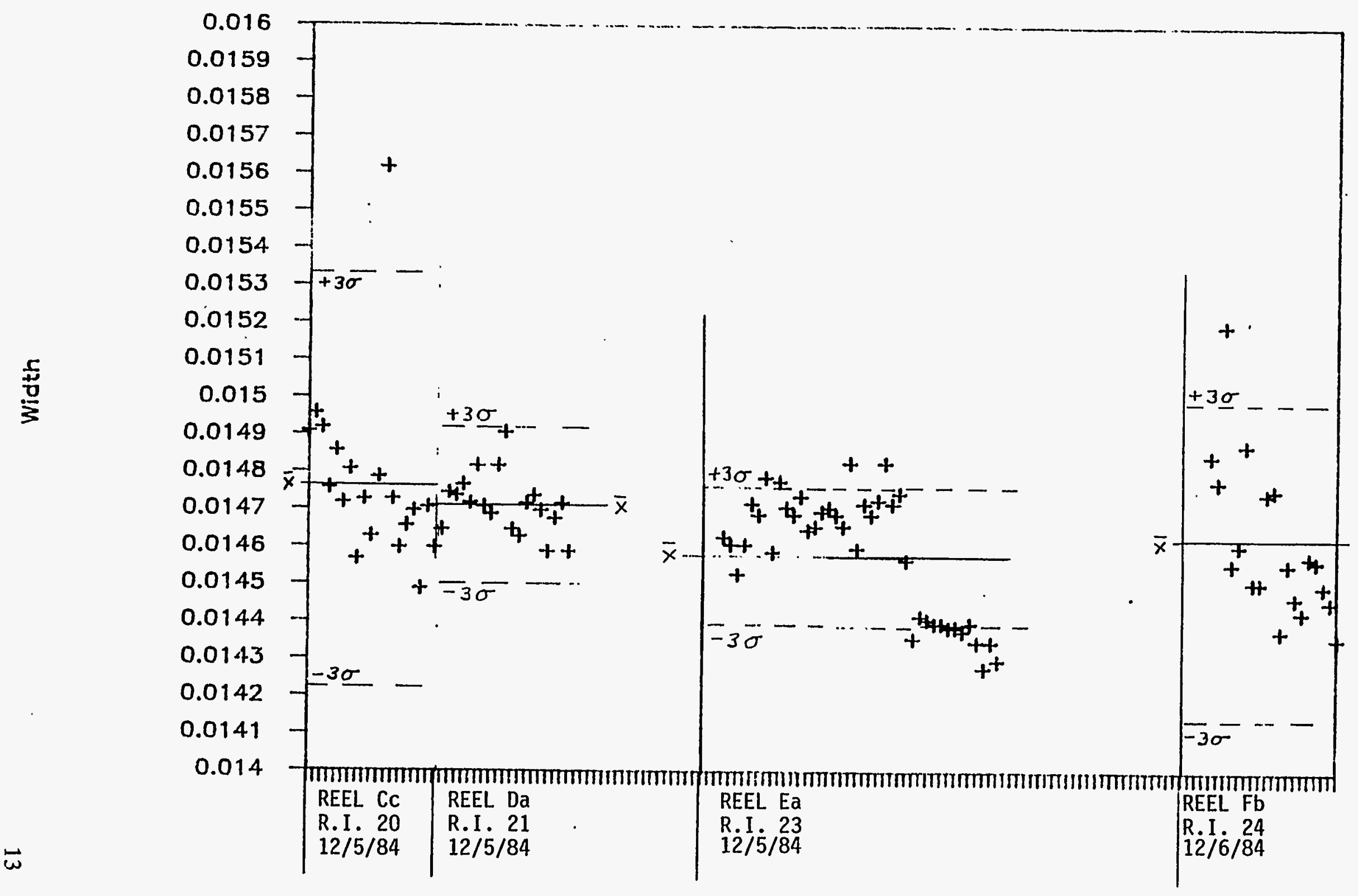




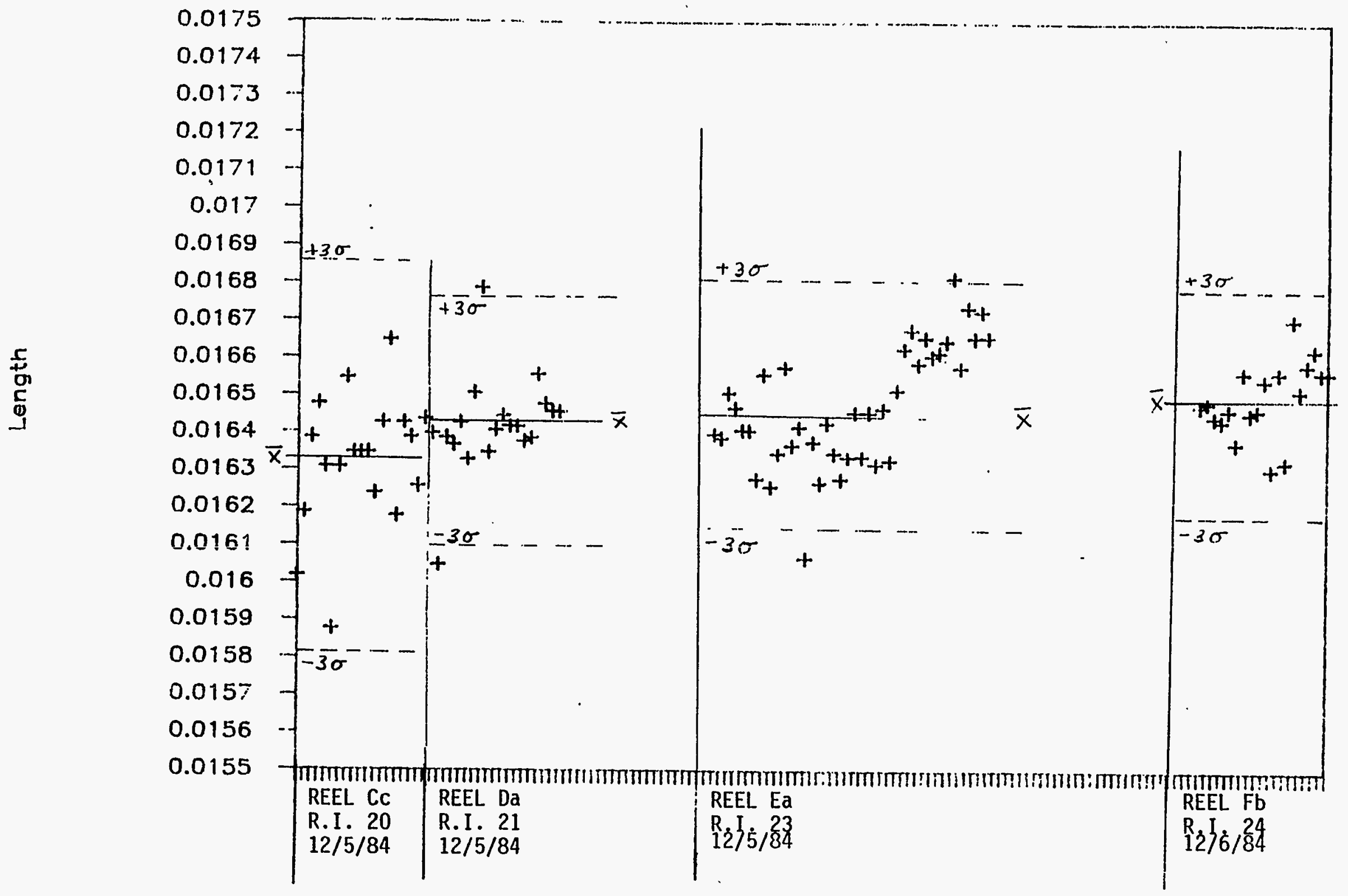


PHOTO TOOL $40\left(.020 \times .020^{\prime \prime}\right)$

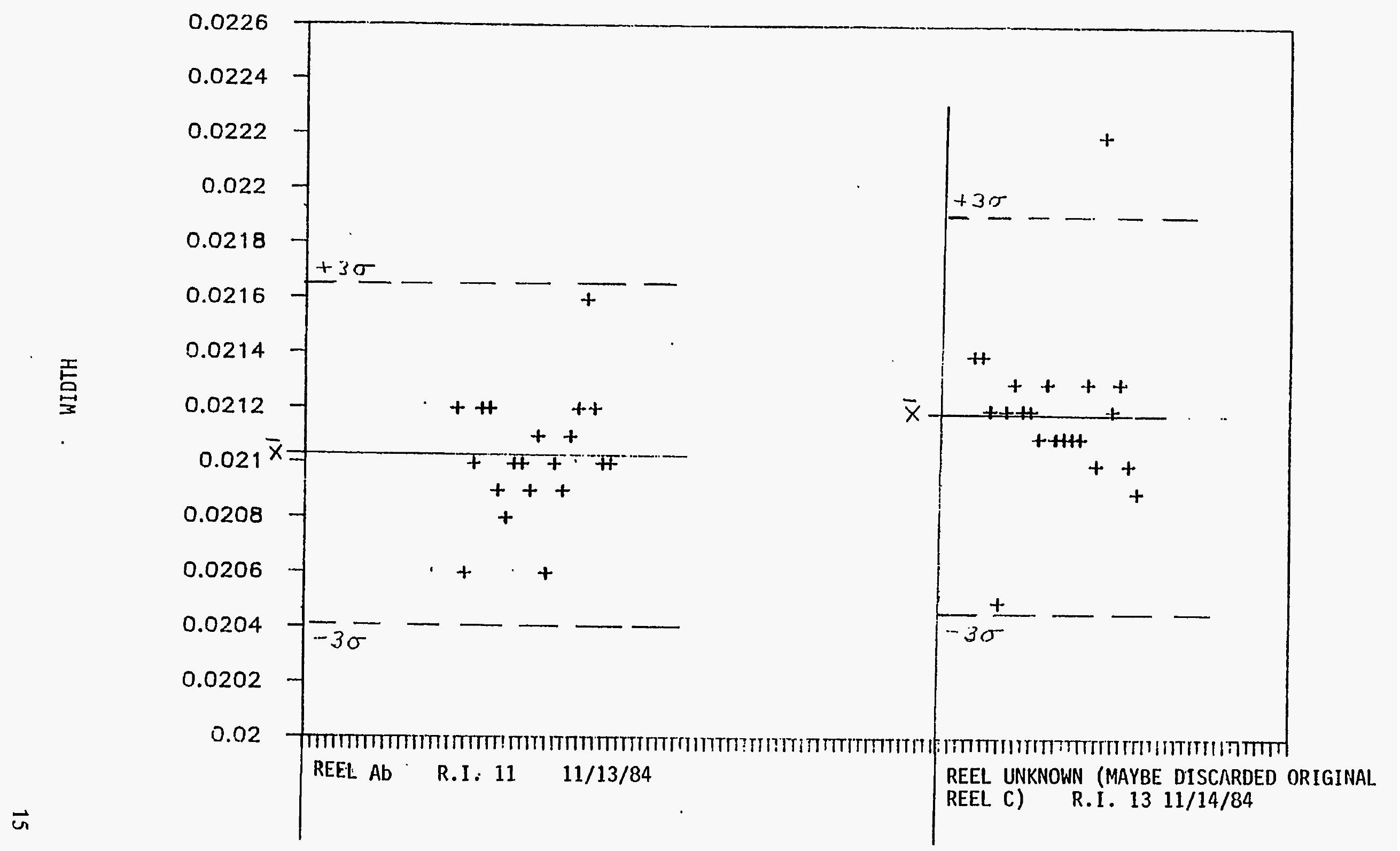


PHOTO TOOL $40\left(.020 \times .020^{\prime \prime}\right)$

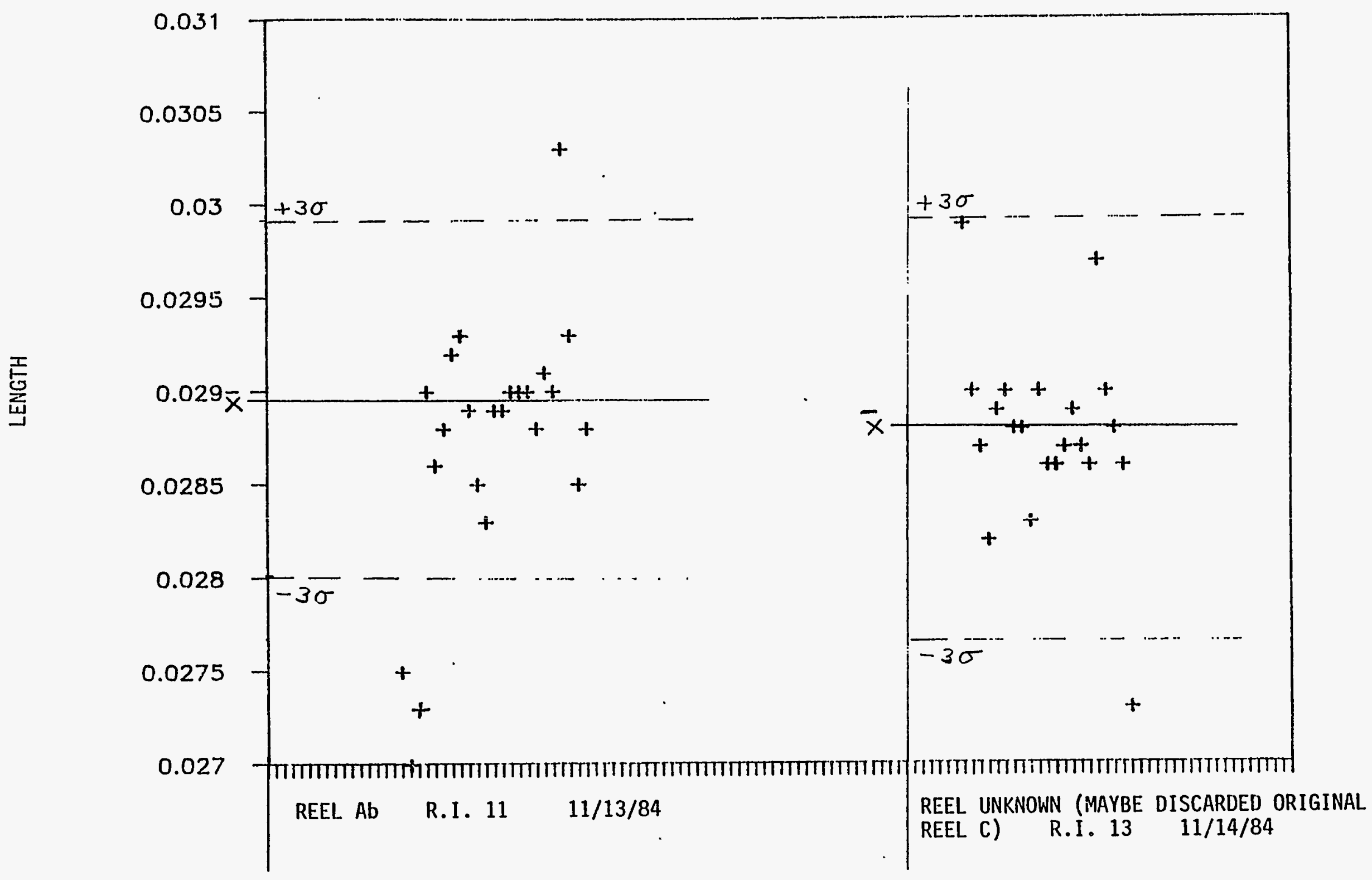




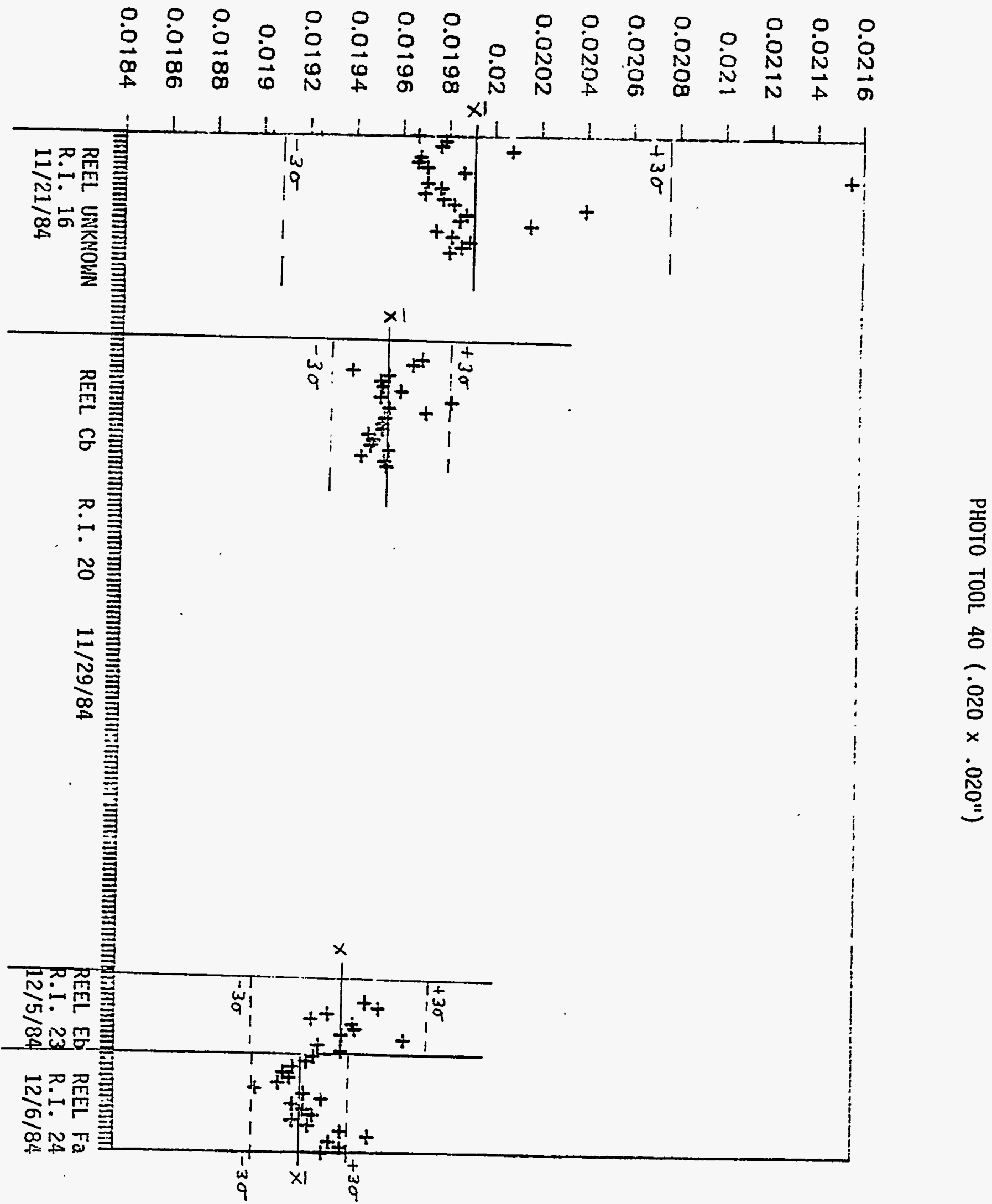




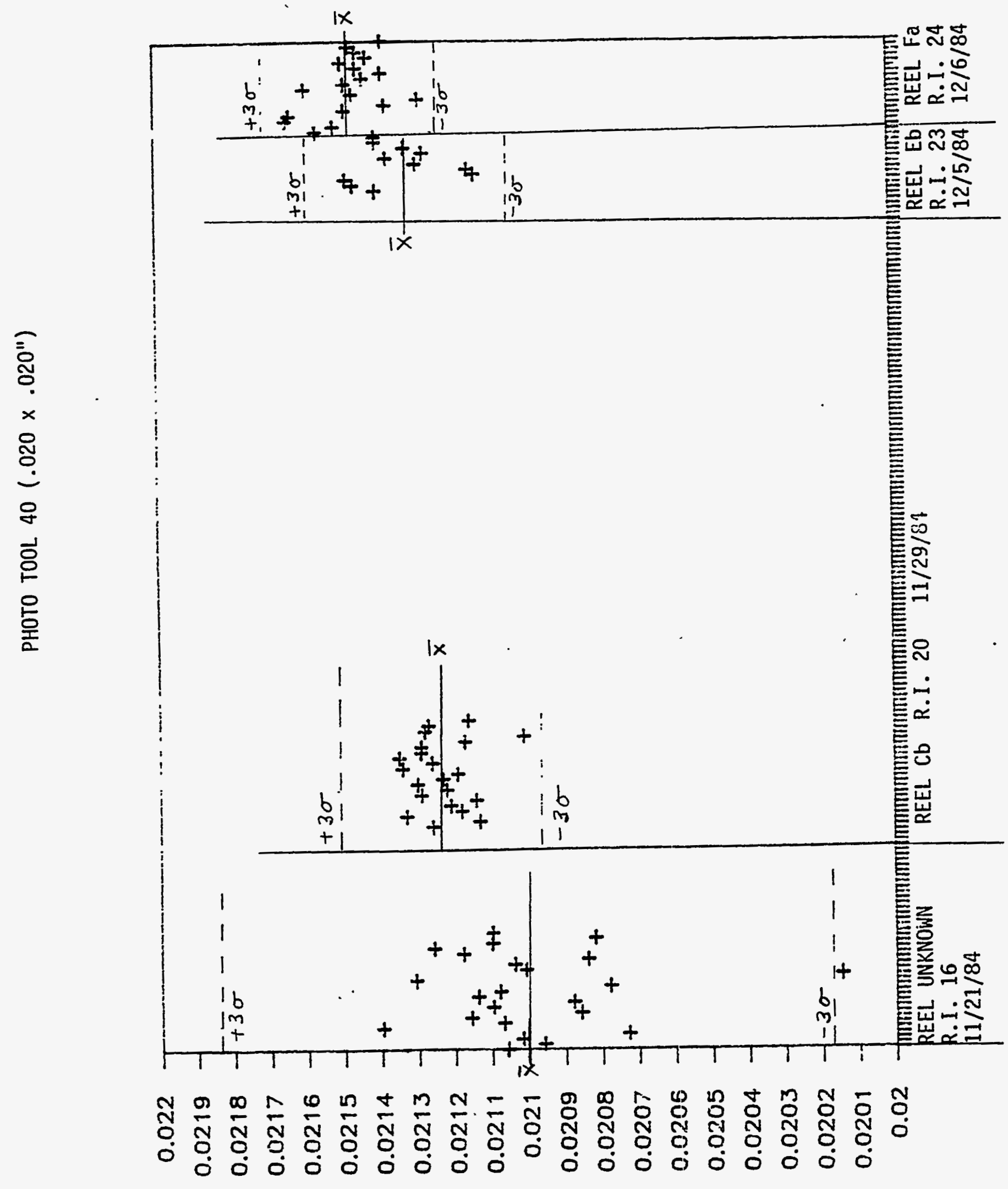




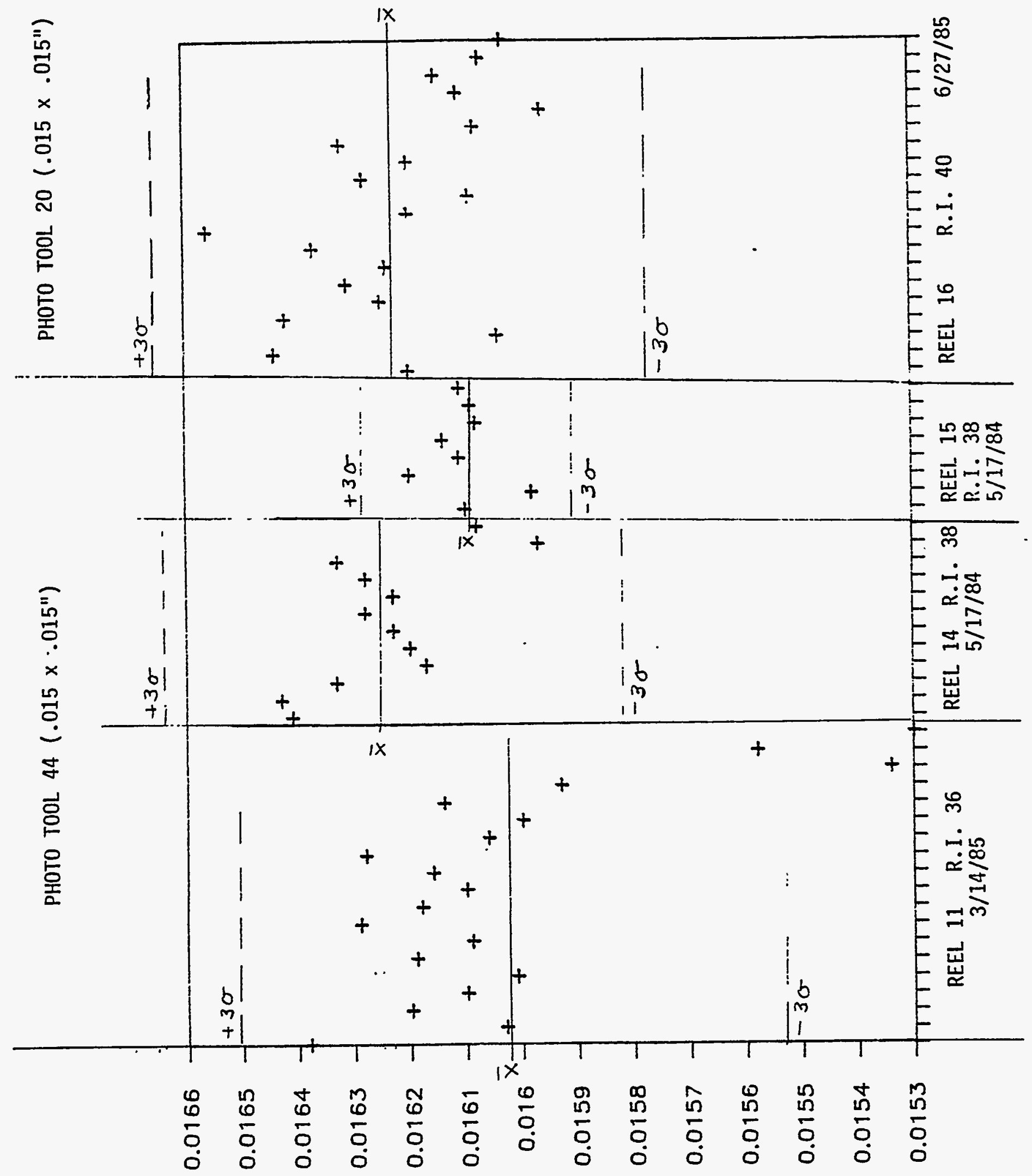




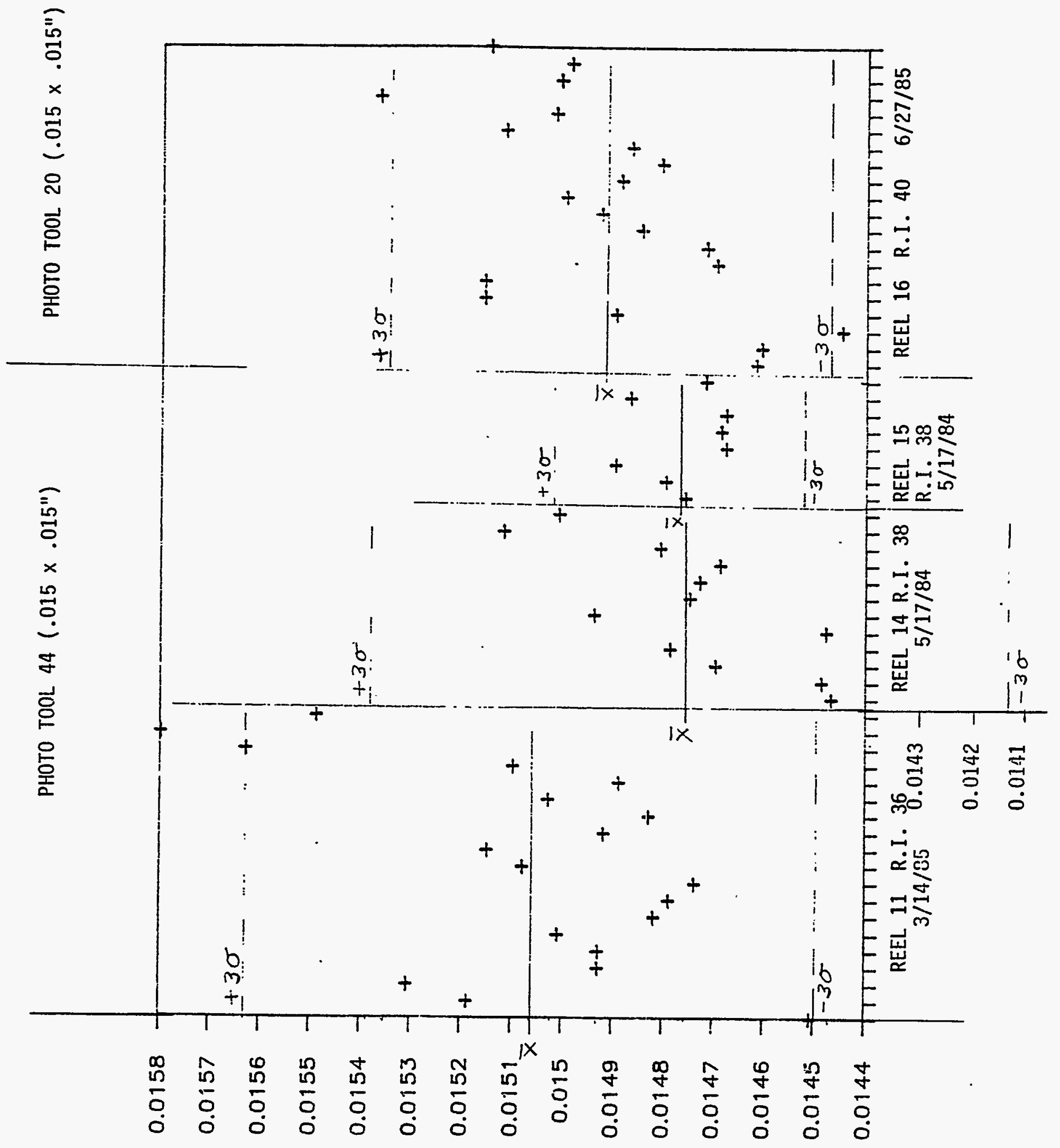




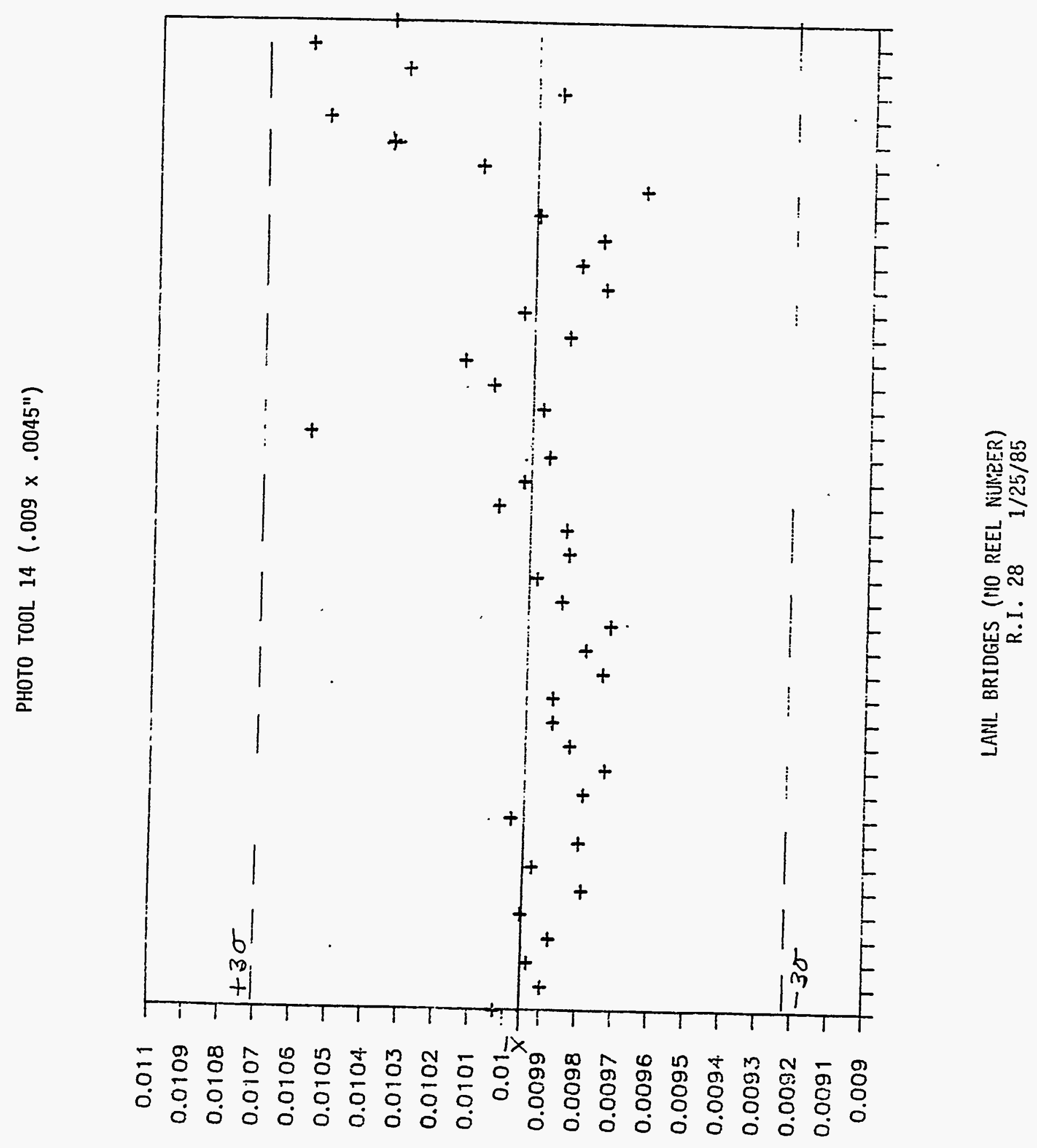


PHOTO TOOL $14(.009 \times .0045 ")$

N

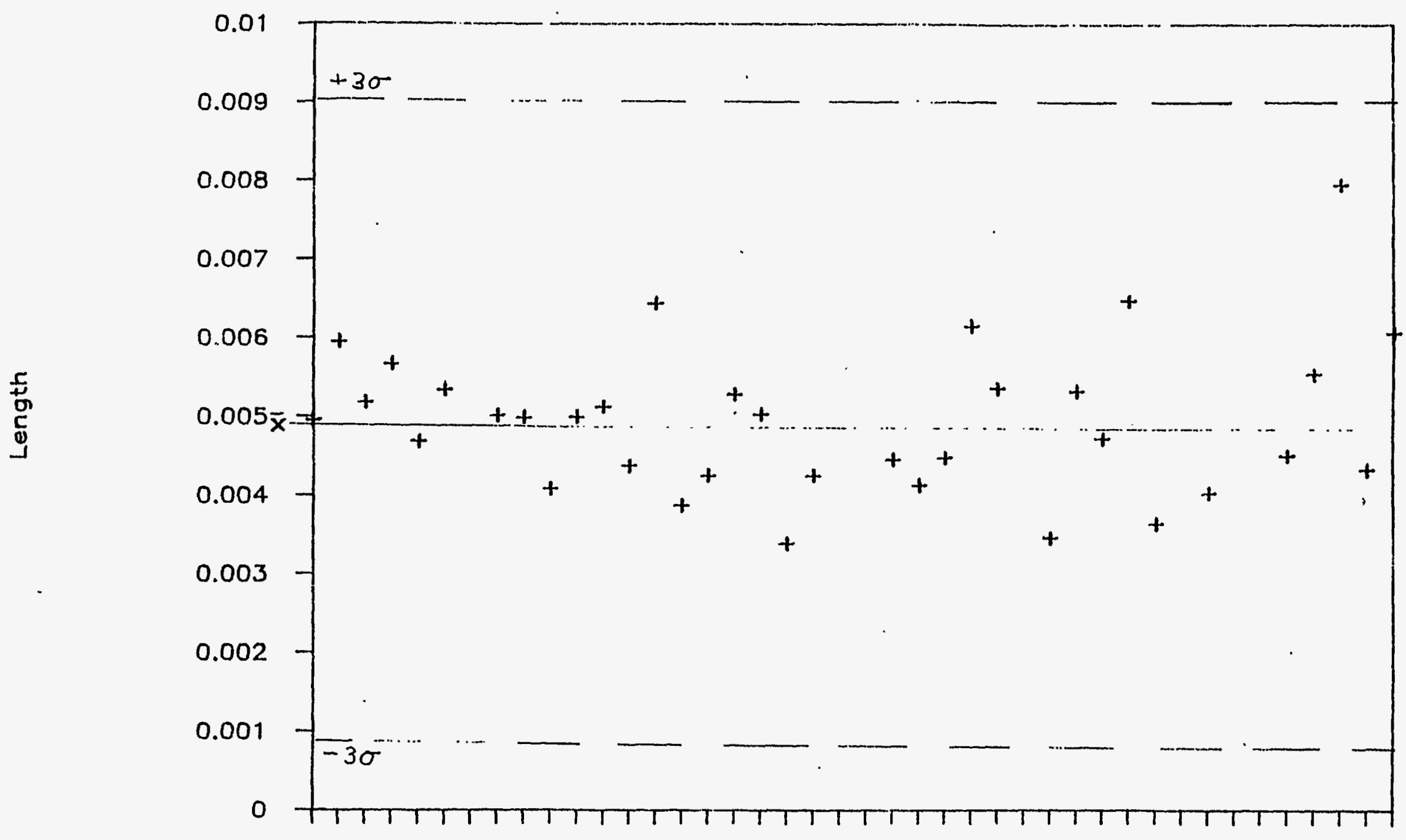

LANL BRIDÛES (NO REEL NUMBCR)

R.I. $281 / 25 / 05$ 


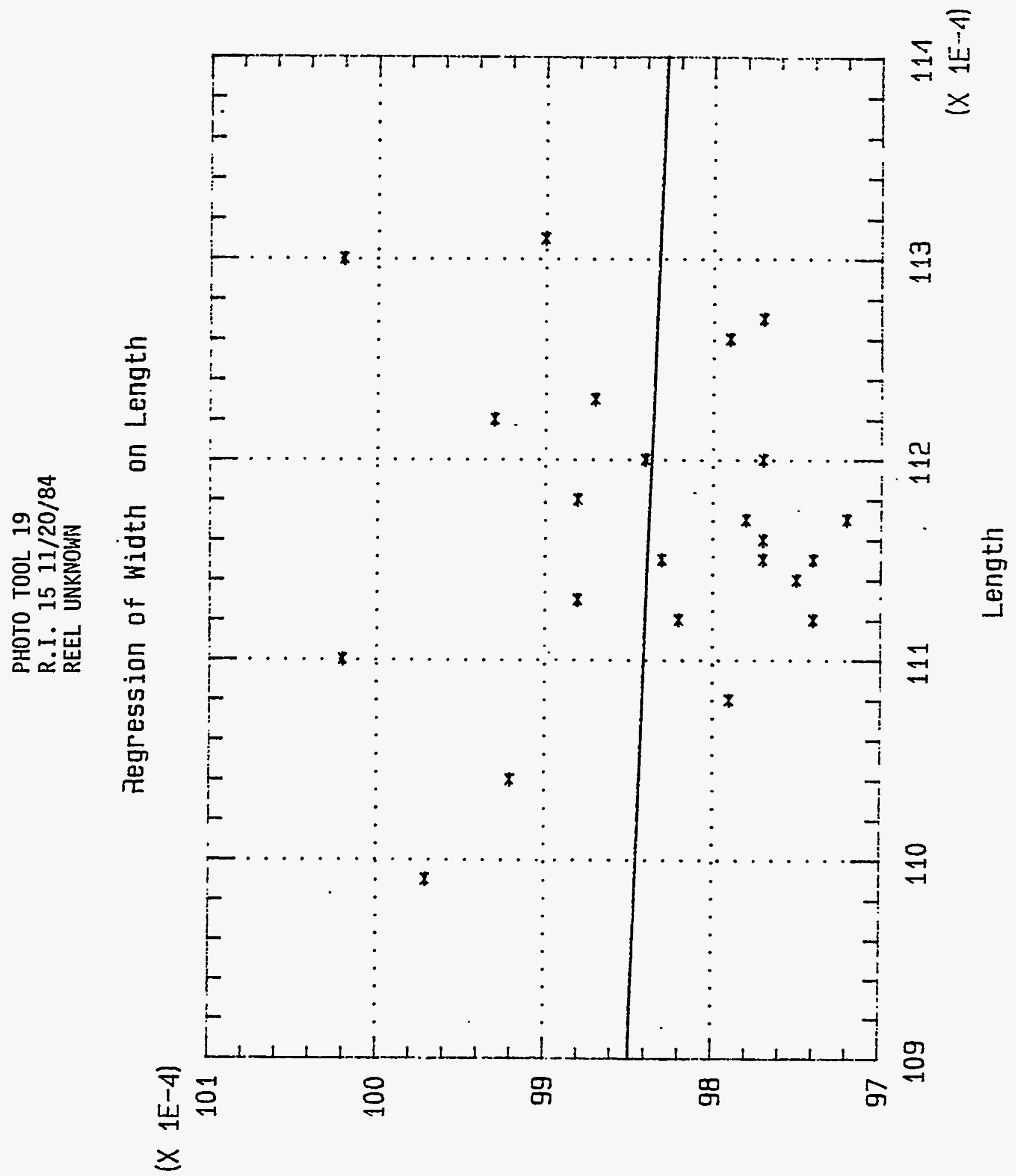


Regression of Width on Length

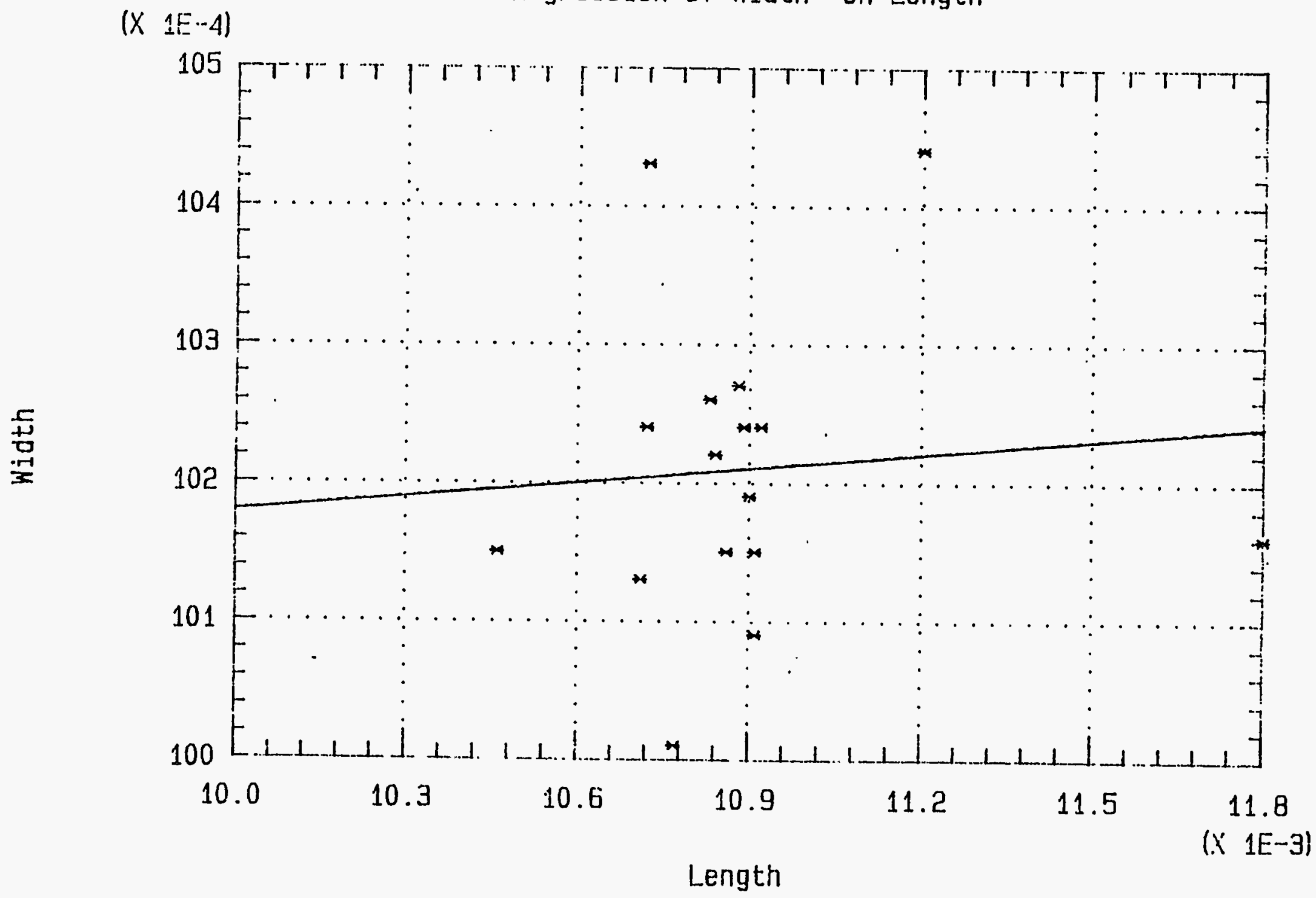




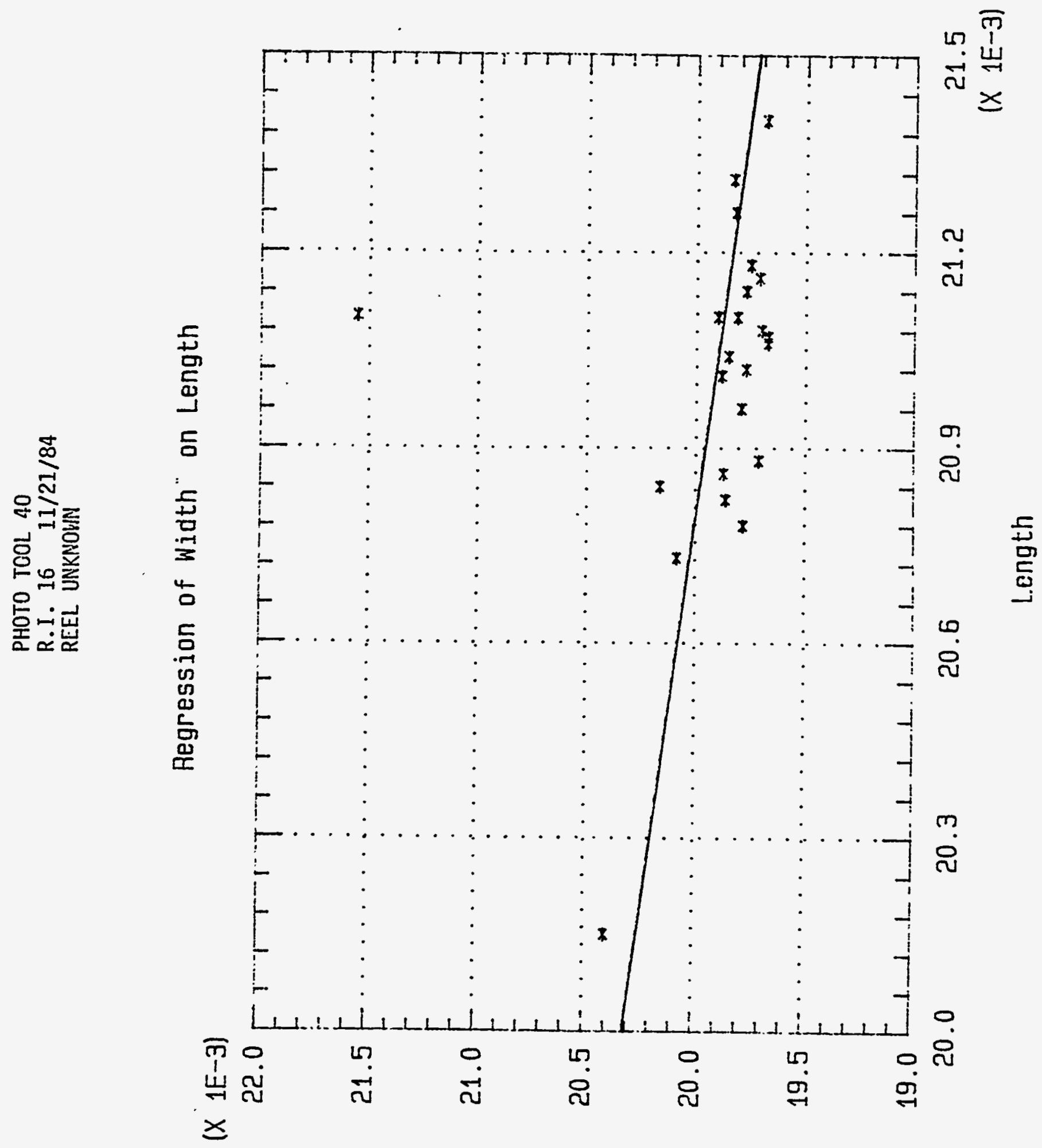




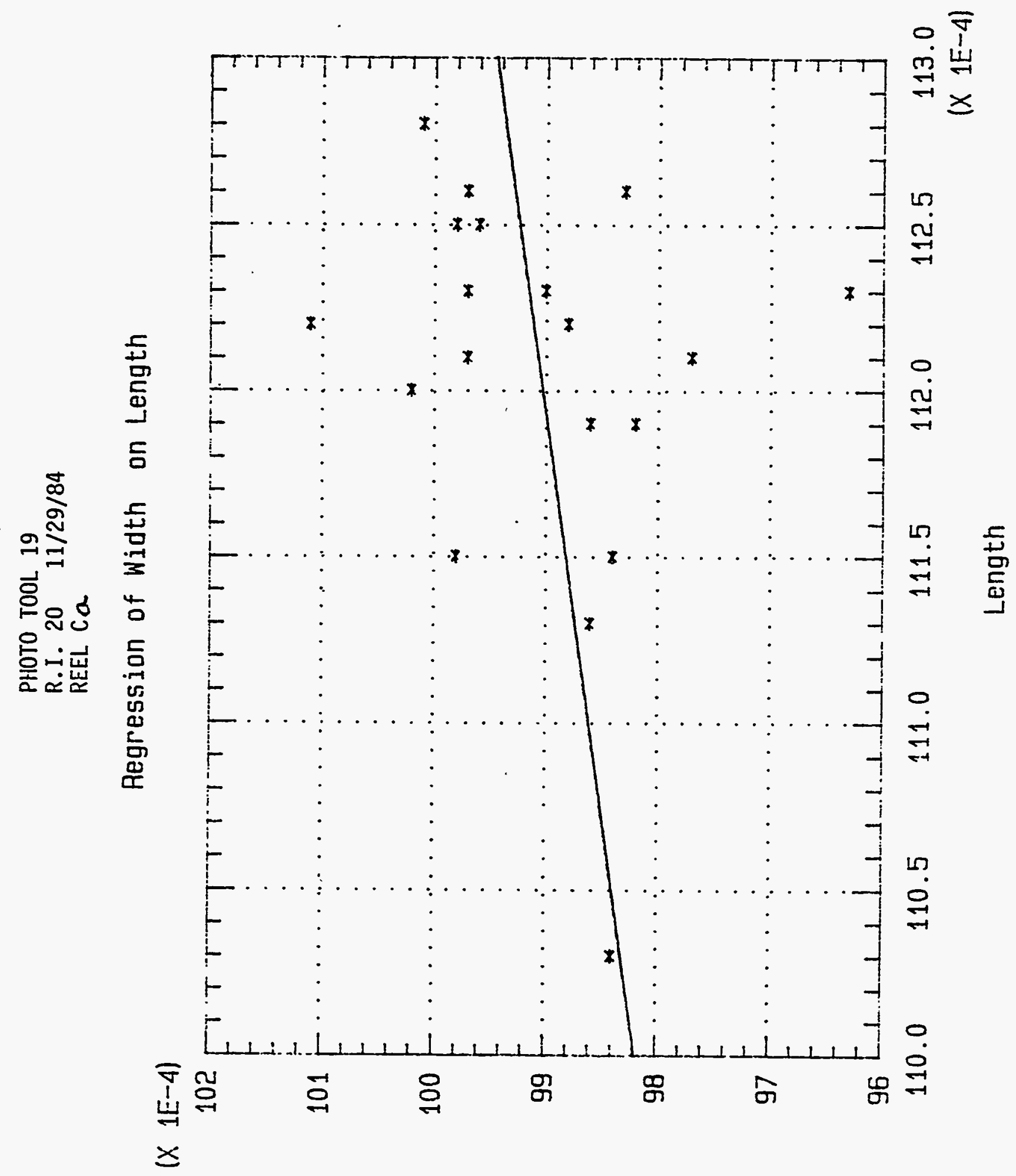




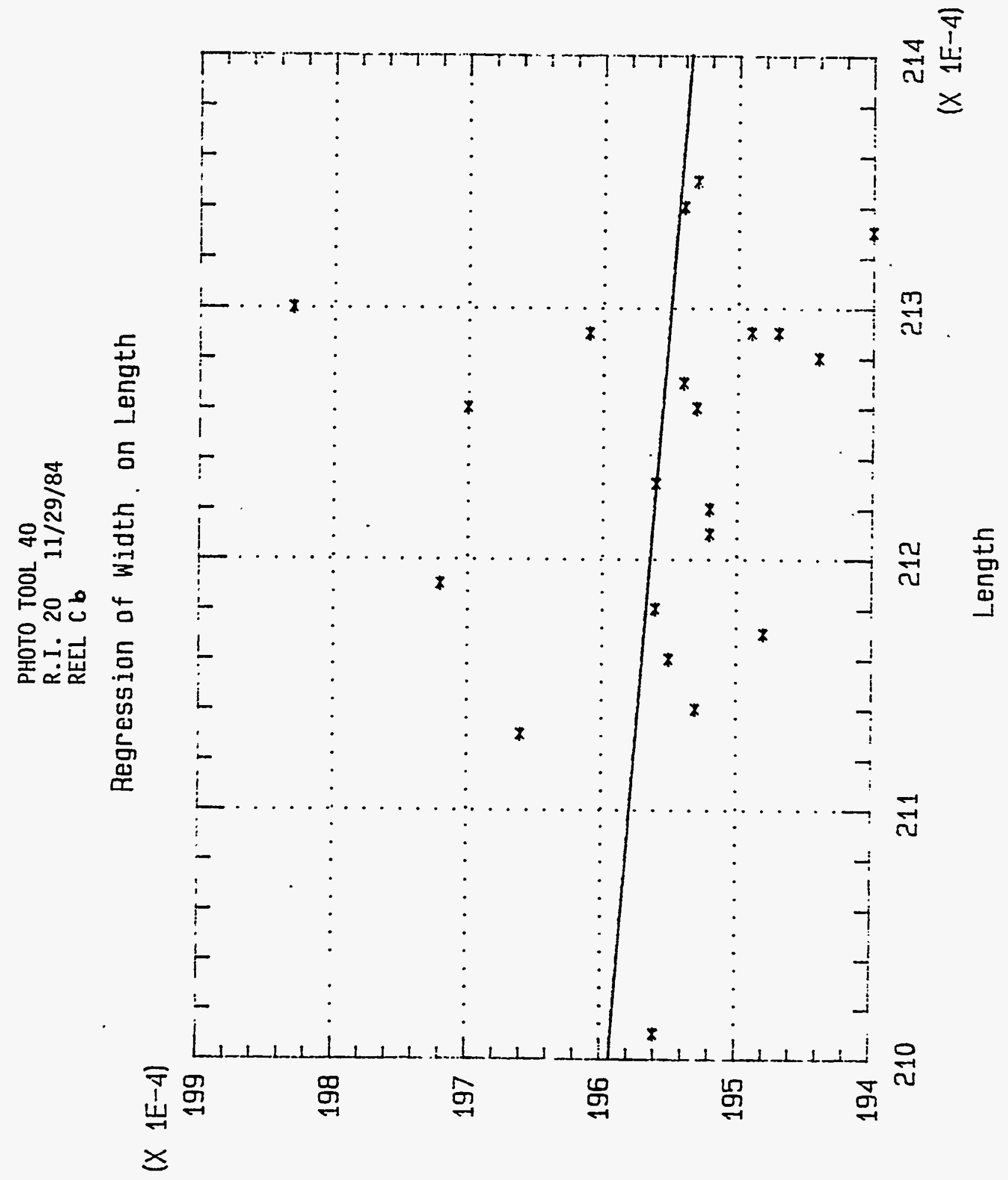




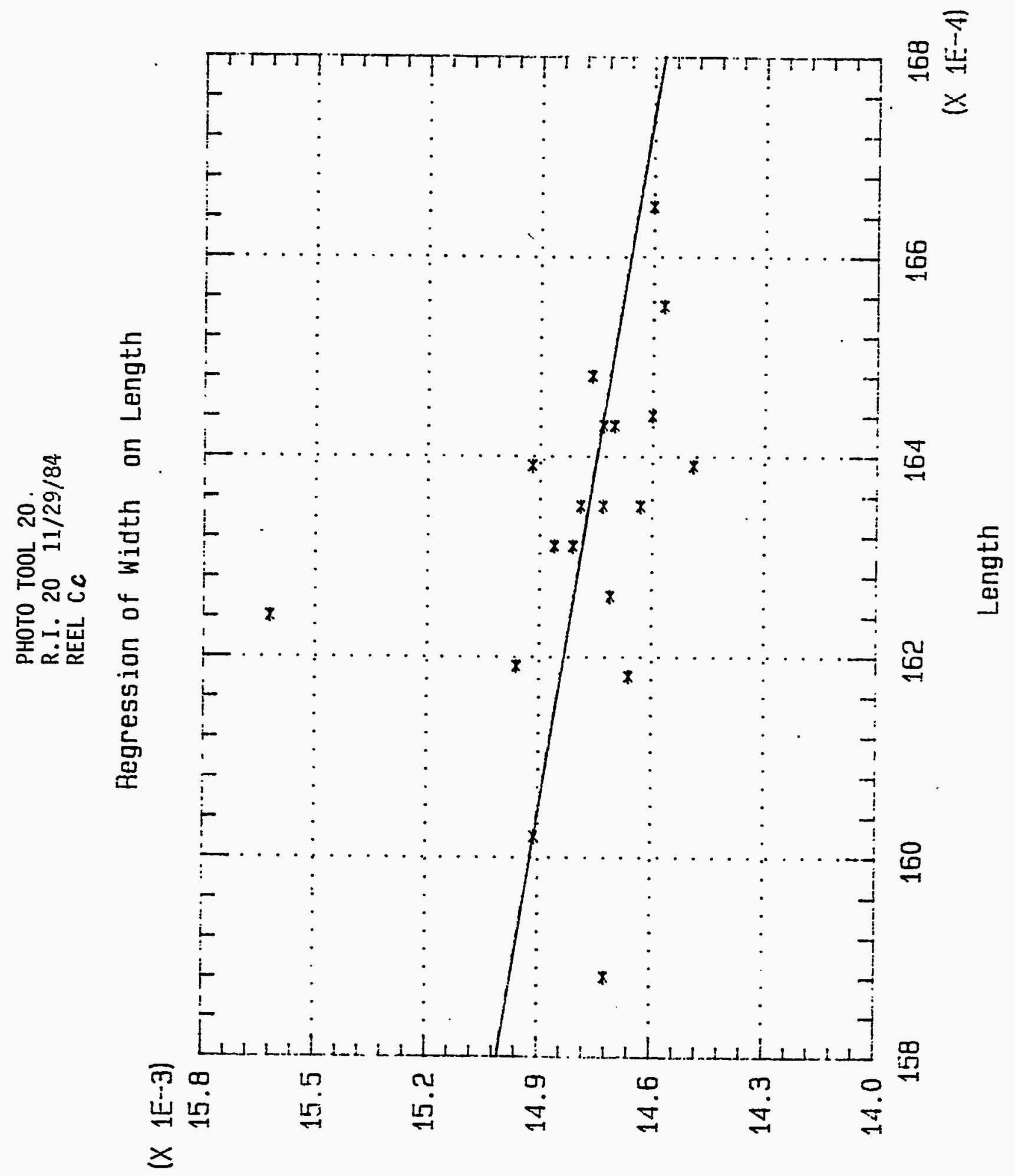


WIDTH STATISTICS

\begin{tabular}{|c|c|c|c|c|c|c|}
\hline REEL NO & R.I. NO. & PHOTO TOOL & AND SIZE & $X-B A R$ & SIGMA & REMARKS \\
\hline $\mathrm{Aa}$ & 11 & PT 19 & .010 & .01080 & .000072 & \\
\hline$A b$ & 11 & PT 40 & .020 & .02103 & .000205 & \\
\hline B & 12 & PT 19 & .010 & .01117 & .000161 & \\
\hline$?$ & 13 & PT 19 & .010 & .01111 & .000130 & MAYBE ORIGINAL REEL C THAT \\
\hline$?$ & 13 & PT 40 & .020 & .02120 & .000244 & " \\
\hline$?$ & 13 & PT 20 & .015 & .01636 & .000171 & " \\
\hline$?$ & 15 & PT 19 & .010 & .00984 & .000100 & \\
\hline$?$ & 16 & PT 19 & .010 & .01021 & .000116 & \\
\hline$?$ & 16 & FT 40 & .020 & 01991 & .000279 & \\
\hline $\mathrm{Ca}$ & 20 & PT 19 & .010 & .00991 & .000090 & \\
\hline $\mathrm{Cb}$ & 20 & PT 40 & .020 & .01956 & .000090 & \\
\hline Cc & 20 & PT 20 & .015 & .01478 & .000184 & \\
\hline $\mathrm{Da}$ & 21 & PT 20 & .015 & .01472 & .000071 & \\
\hline $\mathrm{Db}$ & 21 & PT 19 & .010 & .00974 & .000082 & \\
\hline Ea & 23 & PT 20 & .015 & .01459 & .000062 & \\
\hline El & 23 & PT 40 & $.0 \varepsilon 0$ & .01943 & .000132 & \\
\hline $\mathrm{Fa}$ & 24 & PT 40 & .020 & .01925 & .000076 & \\
\hline $\mathrm{Fb}$ & 24 & PT 20 & .015 & .01462 & .000154 & \\
\hline ? & 28 & PT 14 & .009 & .00996 & .000250 & LANL BRIDGES \\
\hline
\end{tabular}




\begin{tabular}{|c|c|c|c|c|c|c|}
\hline sə[dures әм!าеquәsәudsəy $0 Z$ & $9 \mathrm{~b} T 000^{\circ}$ & $260 \tau 0^{\circ}$ & GI0 ${ }^{\circ}$ & $02 \mathrm{ld}$ & $0 t$ & 9I \\
\hline saldues $ә \wedge ! q$ quәsəuday 8 & $180000^{\circ}$ & $9 \angle t I 0^{\circ}$ & STO ${ }^{\circ}$ & 加 Id & $88 \varepsilon$ & SI \\
\hline \multirow[t]{2}{*}{ səןdues $ә \wedge ! ̨ e q u \partial s \partial\lrcorner d \partial y$ ZI } & $\mathfrak{\tau} 2000^{\circ}$ & $9 \angle \supset I 0^{\circ}$ & SI0 ${ }^{\circ}$ & to id & е8६ & oI \\
\hline & $881000^{\circ}$ & $90 \mathrm{G} \tau 0^{\circ}$ & STO ${ }^{\circ}$ & to Id & $S \varepsilon$ & II \\
\hline SXY甘W & VW9IS & $4 \forall g-x$ & $\overline{3 Z I S C}$ & $01010 \mathrm{Hd}$ & $O N \cdot I \cdot y$ & ON 7338 \\
\hline
\end{tabular}




\section{DELTA BRIDGE LENGTH X-BAR VS. ART WORK}

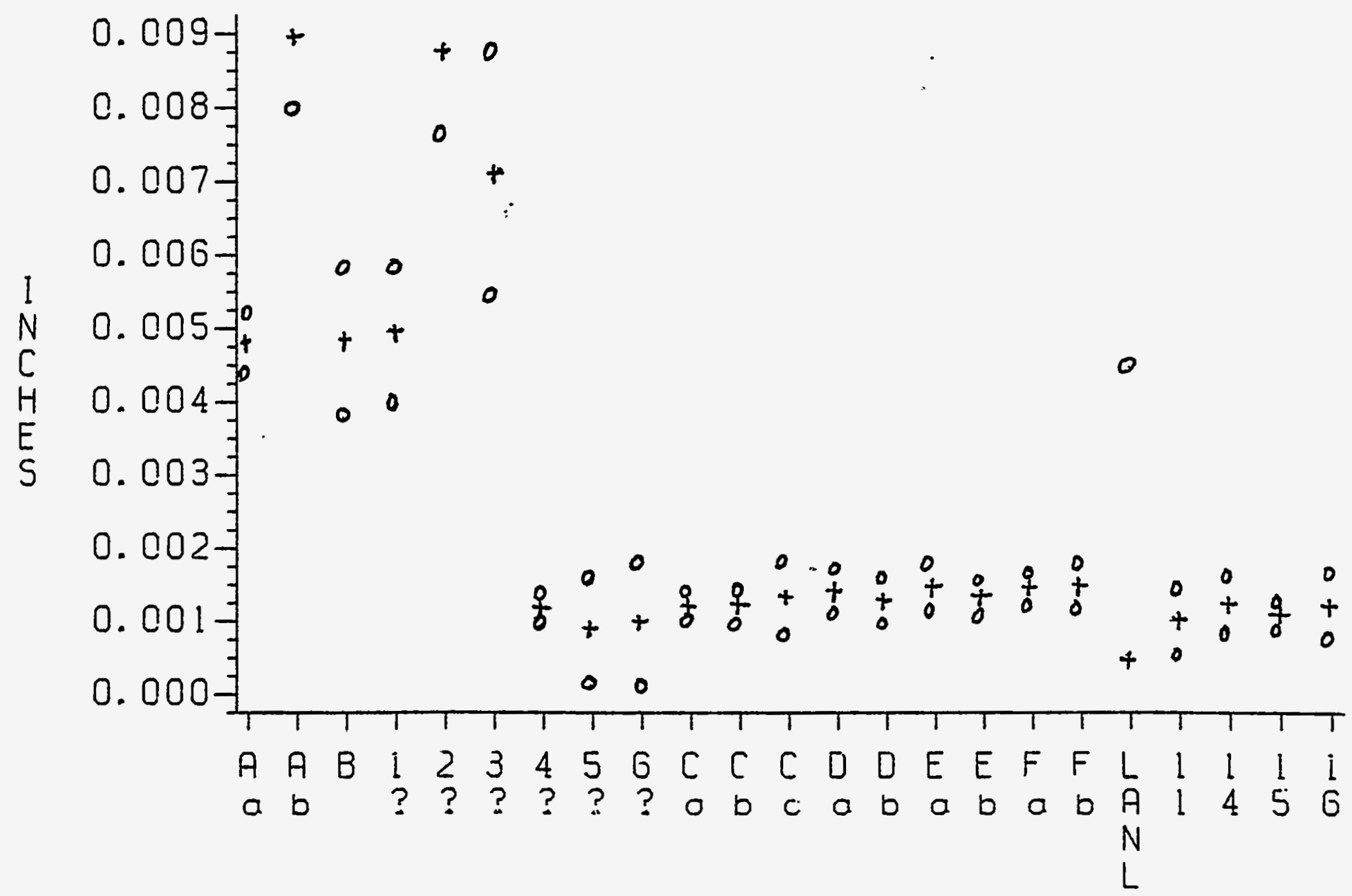

REEL NUMBER 


\section{DELTA BRIDGE WIDTH X-BAR VS. ART WORK}

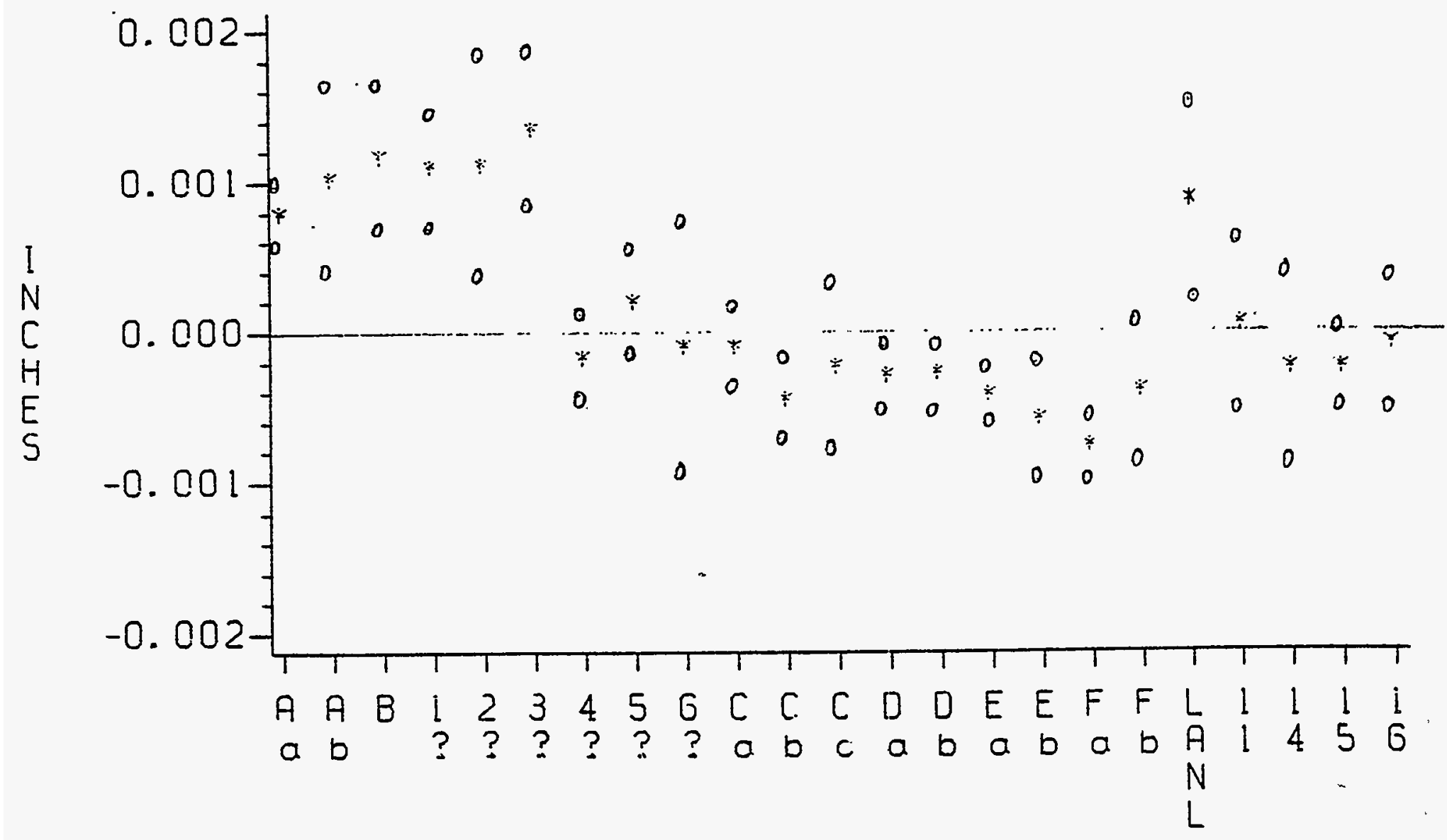

REEL NUMBER 


\section{CORRELATION OF MATERIAL THICKNESS AND SIGMA}

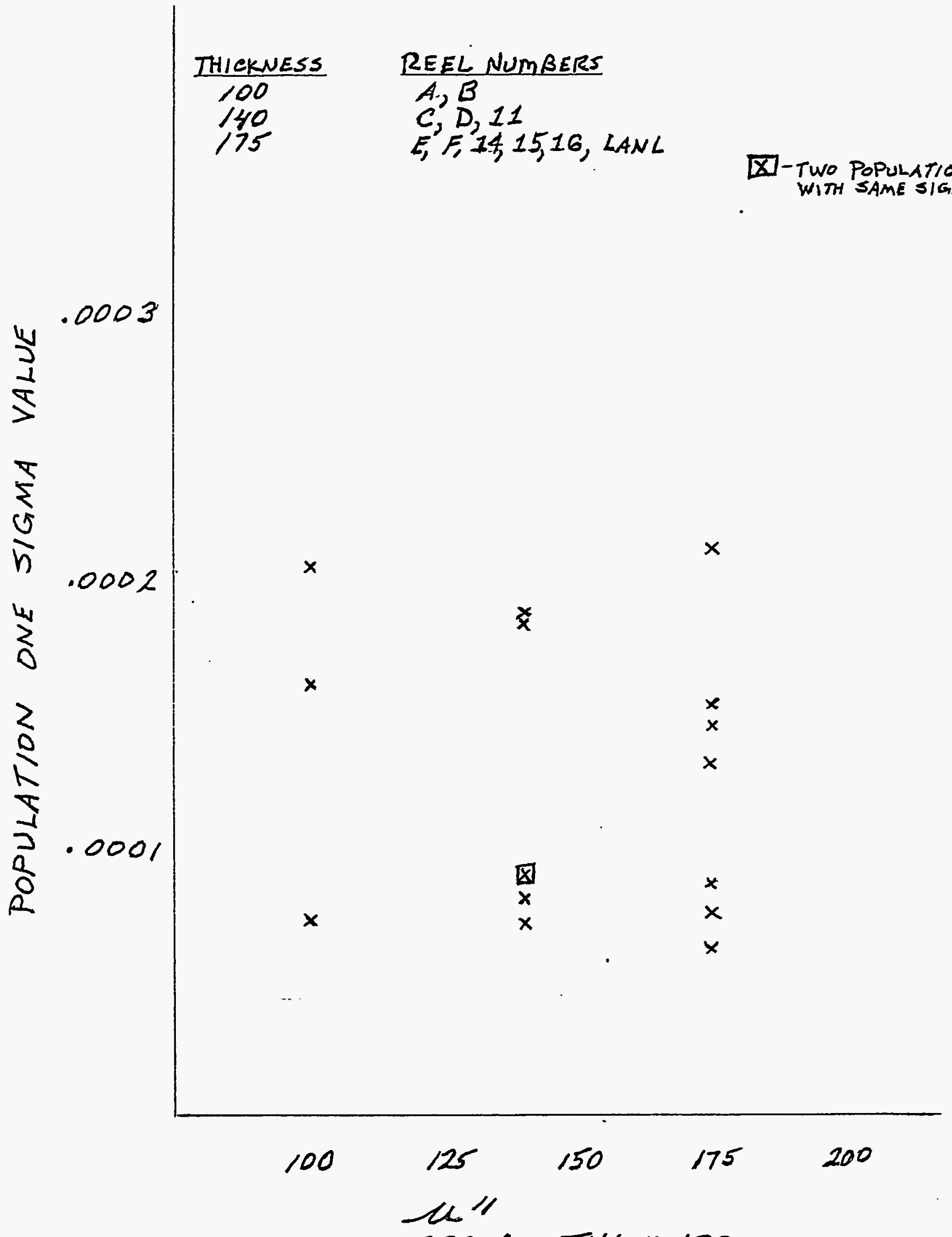

MATERIAL THICKNESS 


$\begin{array}{lll}\text { From } & : \begin{array}{l}\text { Quality Audits \& Systems, Advanced } \\ \text { Devices, F. H. Scott }\end{array} & \text { cc }: \text { G. L. Houston } \\ \text { Date } & : \text { September 24, } 1985 & \text { R. E. Lakes } \\ \text { Subject }: \text { Tape Bridge Measurement Capabilities } & \text { G. L. Morris } \\ \text { Reference }: & \text { M. E. Sterrett } \\ & & \text { J. A. Thomes } \\ & & \text { D. F. Wendeln } \\ & \text { A. M. Witzerman }\end{array}$

TO : D. R. Bohl

As part of a capability study being performed on the tape bridge process, an assessment was made of the tape dimensional inspection techniques used in Receiving Inspection. A designed experiment was conducted to check for significant differences between operators, between days and within days. Ten parts were read 24 times each for a total of 240 readings. An analysis of variance found a significant difference between days and a day unit interaction. The pooled sigma of the 10 individual sigmas was .00019" for bridge width, and .00053" for bridge length. These sigmas far exceeded the .000050" sigma that was anticipated. Figures 1 and 2 graphically display the average, and plus and minus three sigma values for each of the 10 units.

The inspection process was evaluated and three changes/improvements were made to decrease the variance:

1) The staging technique was made more rigid by using additional table clamps to assure the glass "envelope" holding the bridges did not shift while making the measurements.

2) The number of geometry points on the bridge used for locating and/or measuring was increased from the 5 to 7 range, to a 13 to 20 range. (Use of additional points would tend to average out any single erroneous location or measurements.)

3) The means of determining width was made more direct. Two techniques were tried: 13 individual paired width readings that were mathematically averaged; and 13 readings along each edge of the bridge to determine two best fit lines and the distance/width between them.

Following these changes, the bridge width of ten parts was measured five times. The pooled sigma for these 50 readings was $.000047^{\prime \prime}$ (Figure 3 ) for the mathematical average concept, and $.000066^{\prime \prime}$ 
(Figure 4) for the best fit line concept. These sigmas are believed to be the best that can be obtained given the inherent inaccuracies within the vidicom itself.

This analysis was conducted on "square" bridges which have parallel edges. Additional evaluation is needed on "radiused" bridges that blend at the mid-point of the bridge, and thus have only a single point of uniform width. Any $X$-axis error in locating the blend point will result in wider/erroneous width readings. 


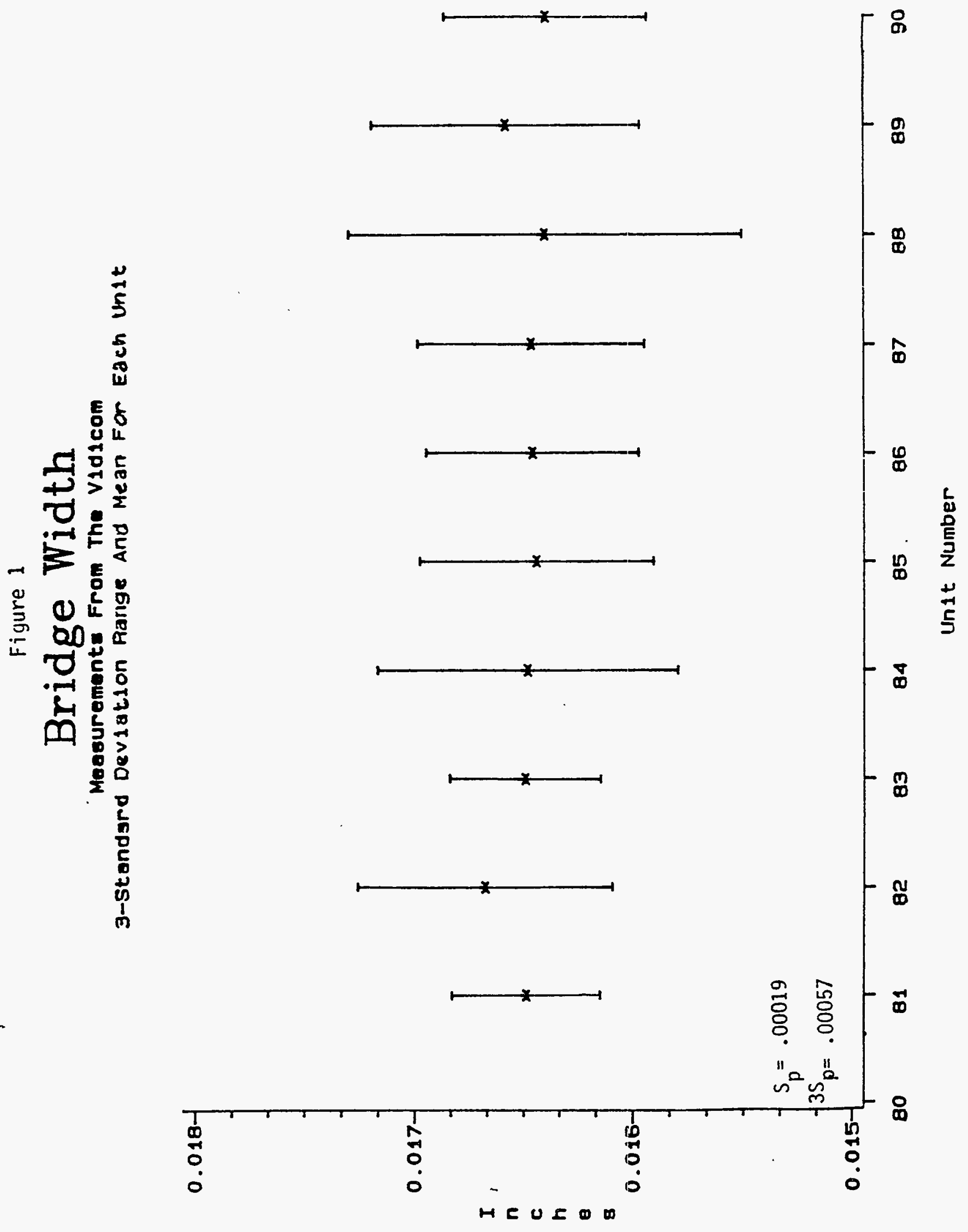




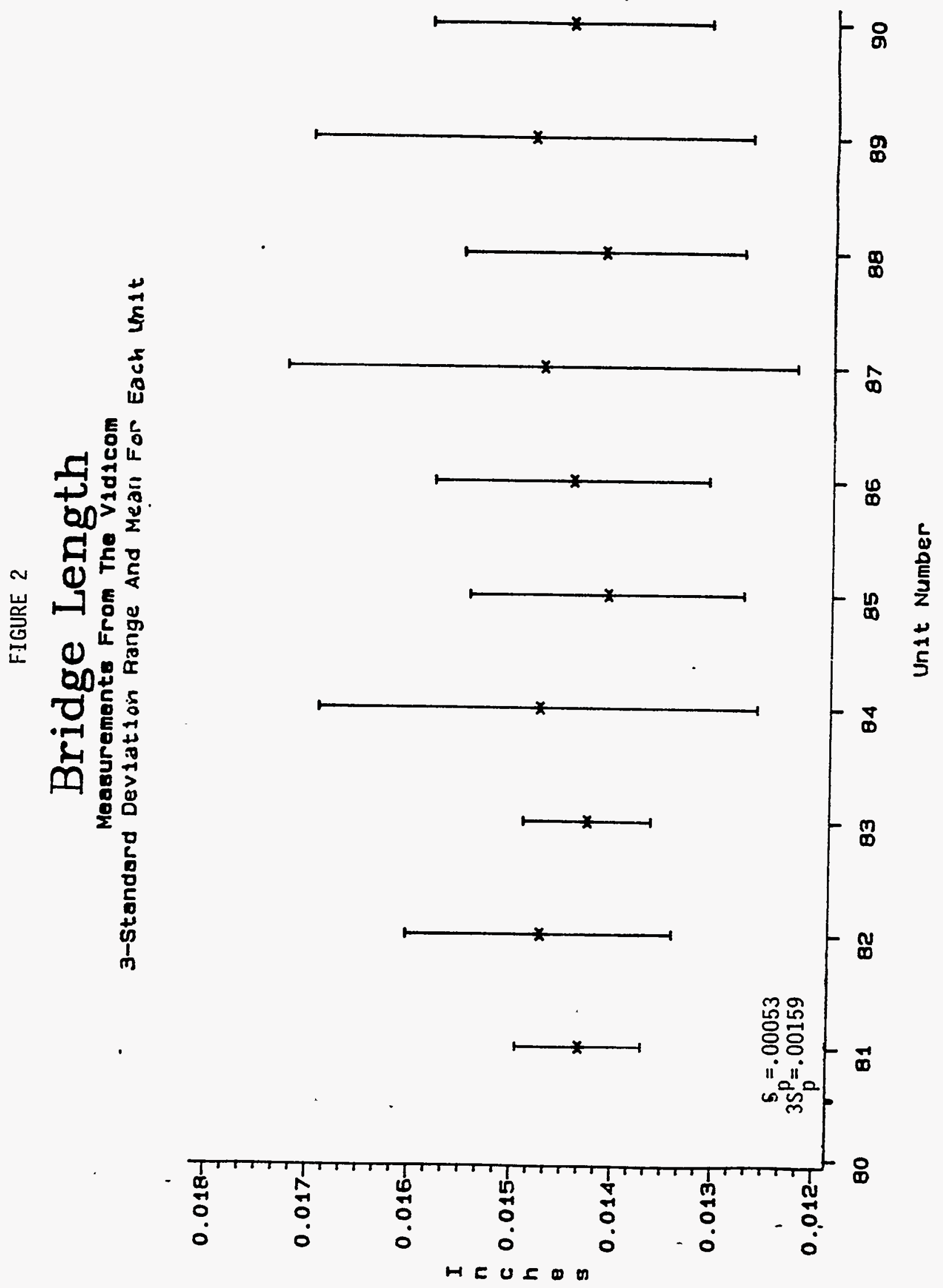


FIGURE 3

\section{BRIDGE WIDTH PRECISION STUDY}

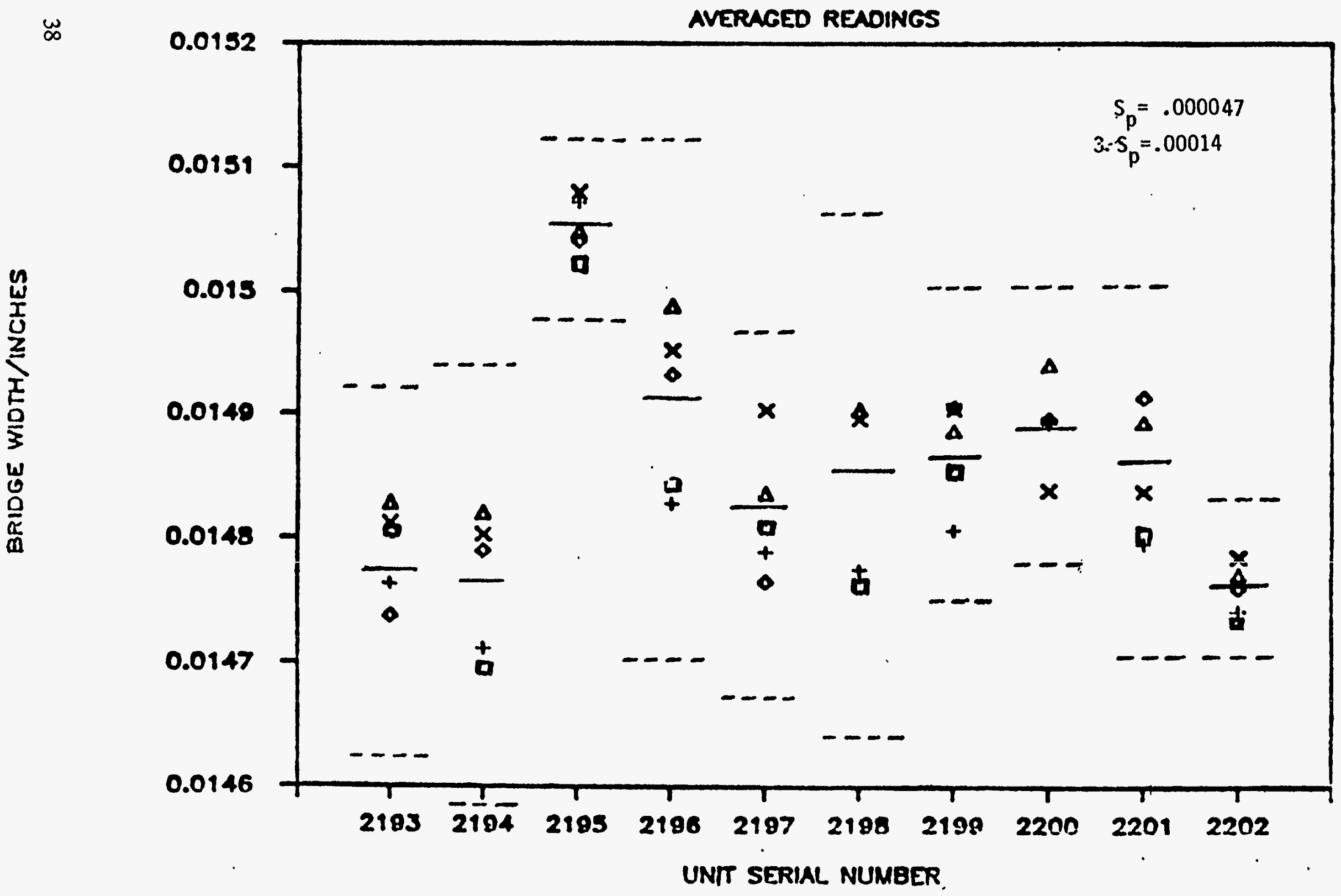




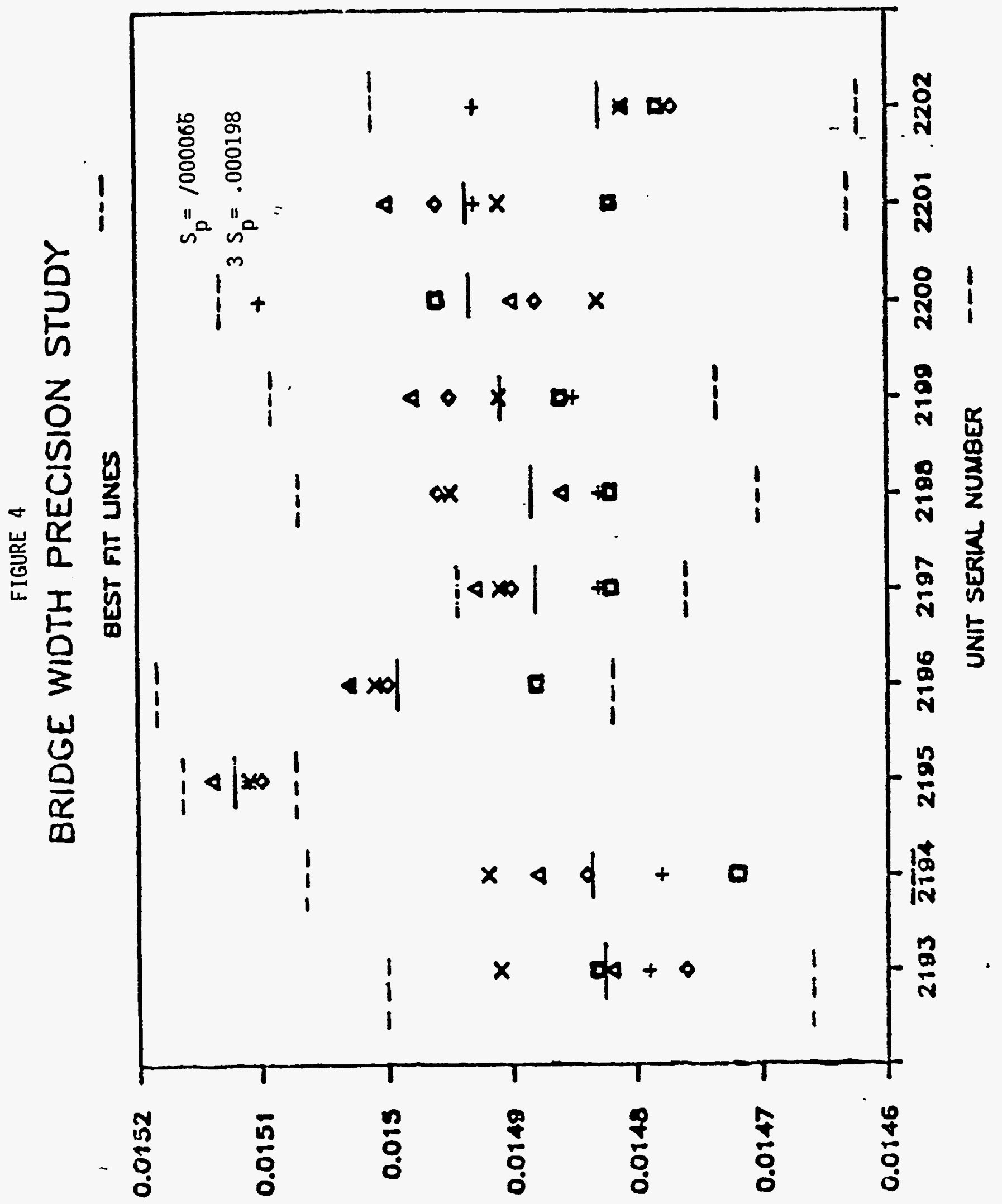




\section{Acknowledgments}

The author would like to thank F. H. Scott for his contribution to tape process development. The work detailed in this report is solely his. The author claims no recognition for the research, only for the effort required to document it. The author also extends special recognition to those Production, Quality, and Development personnel who contributed to the data collection and reduction. 


\section{Glossary}

Artwork

Bridge

Bridge Length

Bridge Width

Flyer

Kapton

LANL

LLNL

Microclad

Phototool

Radius Bridge

Reel

Receiving Inspection

Roll

SNLA

Square Bridge

Tape Process

Vidicom

Wet Processing
See phototool.

Functioning copper foil portion of a slapper that drives the flyer.

Dimension of a bridge parallel to the electric current.

Dimension of a bridge perpendicular to the electric current.

Portion of a slapper detonator driven by the rapid ionization of the bridge element (usually 0.001-in. to 0.002-in. Kapton).

Trade name for a polyimide product produced by duPont.

Los Alamos National Laboratory.

Lawrence Livermore National Laboratory.

Trade name of a copper-coated polyimide produced by Fortin Industries and used in fabricating bridges and flyers.

Tool used to create a circuit image. A phototool contains the image of the desired circuit and exposes the image onto a chemically conditioned surface.

Bridge for which the length is defined by a radius such that the center of the bridge is in the thinnest region.

Sample of material slit to a width of $35 \mathrm{~mm}$ and wound around a core.

Area at Mound where incoming material is inspected for conformance to specifications.

Sample of material as purchased from a vendor. A roll is the original width, usually 12 in. A roll is later slit to thinner widths to become reels.

Sandia National Laboratories, Albuquerque.

A bridge for which the width is uniform from end to end.

Method of producing flexible circuits in a reel-to-reel fashion. This process is unique to Mound.

Vision system produced by Vidicom used to inspect bridge length and width.

Process of laminating, exposing, developing, etching, and stripping a flexible circuit image. 


\section{Distribution}

\section{EXTERNAL}

S. G. Barnhart, Sandia National Laboratories, Albuquerque

G. E. Dahms, Sandia National Laboratories, Albuquerque

R. McCormick, Los Alamos National Laboratory

J. A. Morley, DOE/DAO

\section{INTERNAL}

K. P. Armstrong

J. R. Brinkman

T. M. Bruggeman

T. A. Demana

M. P. Fisher

E. D. Freese

E. D. Hill

G. L. Houston

M. A. Huelskamp

C. W. Huntington

D. P. Kelly

D. E. Michel

G. L. Morris

R. S. Ramachandran

M. D. Stoltz

J. A. Thomes

R. E. Vallee

S. I. Waskey

Publications

Library (10) 